\title{
The 3-machines energy transition model: exploring the energy frontiers for restoring a habitable climate
}

\author{
Harald Desing*1, Andreas Gerber ${ }^{1}$, Roland Hischier ${ }^{1}$, Patrick Wäger ${ }^{1}$, and Rolf Widmer ${ }^{1}$ \\ 1 Empa - Swiss Federal Laboratories for Material Science and Technology, Lerchenfeldstrasse \\ 5, 9014 St. Gallen, Switzerland \\ * corresponding author: harald.desing@empa.ch
}

\begin{abstract}
Along with the increasing urgency for climate action, more and more ambitious transformation pathways need to be conceived. The maximum speed of change is thereby constrained by biophysical limits. Even though it is essential for climate action to know what transformation pathways are still feasible from a biophysical perspective, there is a lack of studies and models exploring these frontiers of climate action. This paper introduces the 3-machines energy transition model, representing a first step to explore the energy frontiers for a complete phase out of fossil fuels and reducing the atmospheric $\mathrm{CO}_{2}$ concentration below $350 \mathrm{ppm}$. Simulation experiments with this model show that even if all economic and societal obstacles could be overcome and the transition would start immediately, global peak heating may exceed $1.5^{\circ} \mathrm{C}$ with a chance of at least $14 \%$. Simultaneously, it is still energetically possible to return to $350 \mathrm{ppm}$ well before the end of this century. While these energy-constrained transformation pathways show that the climate can still be stabilized with a fair chance, they also illustrate the urgency and far-reaching change required in society.
\end{abstract}

\section{Keywords}

climate crisis | energy transition | 350ppm | negative emissions | system dynamics

\section{Introduction}

2 Effects of climate heating, such as heat waves and floods, are unfolding across the globe today [1]. Peak

3 heating of $1.5^{\circ} \mathrm{C}$ is considered the critical threshold beyond which climate tipping points may trigger

4 events threatening ecosystems and humanity [2-6]. In addition to limiting peak heating, climate forcing

5 resulting from excessive greenhouse gas concentrations needs to be reduced in order to stabilize the climate

6 in the long run [5, 7]. An atmospheric $\mathrm{CO}_{2}$ concentration of $350 \mathrm{ppm}$, already higher than during the past 7 one million years [8-11], is considered a safe threshold [5, 7, 12, 13]. Yet, continued burning of fossil fuels s [14-16] rises $\mathrm{CO}_{2}$ concentration faster than ever [17].

There is agreement that a transition from the fossil to a renewable energy (RE) system is key and urgent [16]. Though current RE installation rate is at record heights [18, 19], it is insufficient for staying 
below $1.5^{\circ} \mathrm{C}$ heating $[16,20,21]$, while the remaining carbon budget is rapidly depleted [22, 23]. Most proposed emission pathways allow fossil $\mathrm{CO}_{2}$ emissions to continue, offset by carbon capture and storage (CCS) either at point sources (post combustion) as well as from air with machines (DACCS) and plants (BECCS) [22, 24-27]. Alternative pathways without carbon removal focus mostly on reducing demand [28-30]. Yet, all these proposed pathways exceed $1.5^{\circ} \mathrm{C}$ peak heating with a chance of $>40 \%$ [31] and do not or insignificantly reduce atmospheric $\mathrm{CO}_{2}$ concentration.

Due to continued inadequate climate action, more ambitious and faster transformations become necessary to stabilize the climate [16]. To accelerate climate action, it is important to know the biophysical limits that cannot be transgressed even if all economic and societal obstacles could be overcome. In particular, building the new RE infrastructure requires to "invest" additional energy (i. e. embodied energy). The availability of energy is ultimately limiting the maximum speed of the transition [31, 32]. Besides energy, other constraints such as the availability of natural resources - e. g. materials [33-36], land or water [37, 38] - and social resources - e. g. skills and financial capital - may further slow, but cannot accelerate the transition beyond the energy limit.

Modelling can help to explore the feasible range for climate action and test the effectiveness of climate policy options. Common integrated assessment models (IAMs) explore pathways for reaching specified climate targets from an economic point of view, often based on minimizing total financial costs [39]. In IAMs, assumptions about cost developments and technological progress are necessary while highly uncertain during the modelled fundamental transformations [40] (e.g. they have been pessimistic for PV [41] and may be optimistic for CCS [30]). While current IAMs (e. g. MESSAGE [42], IMAGE [43], POLES [44], REMIND [45], TIAM [46]) consider financial investments for building RE infrastructure, only few (e.g. MEDEAS [47]) include embodied energy investments (see also Section S9). However, financial viability does not guarantee physical viability, especially when investigating rapid change. IAMs allow to simulate transformation pathways in great detail and can, in principle, be adapted to both include energy investments [47] and aim at targets different than minimizing costs. However, their complexity makes it difficult to use them for exploring a wide range of physically possible and climate optimal scenarios. Less complex models have been proposed in literature (e. g. C-ROADS ${ }^{1}$ [48], HARMONEY [49]) to facilitate system understanding and the exploration by societal actors, however, they are not designed for exploring bio-physical and in particular energy frontiers.

This paper aims to fill this gap by exploring the energy frontiers for a twofold societal transformation: (i) the fast and complete transition from fossil to renewable energy and (ii) removing $\mathrm{CO}_{2}$ in excess of $350 \mathrm{ppm}$ permanently from the atmosphere and upper oceans. To this end, the "3-machines" energy transition model is built and presented here. This system dynamics (SD) model (Section 3) is a tool to explore transformations limited by energy for both replacing the current fossil (i. e. the "fossil engine") with a renewable energy system (i. e. the "solar engine") [31] and removing excess $\mathrm{CO}_{2}$ from the atmosphere (i. e. the "carbon scrubber"). It is not intended to model transformations in great detail, but shall serve as an exploration tool for identifying promising strategies, which can be further explored in more detailed modeling frameworks, such as MEDEAS [47]. Simulation experiments (Section 4) allow identifying energy constrained pathways effective in minimizing peak cumulative $\mathrm{CO}_{2}$ emissions, i. e. maximising the chance to stay below $1.5^{\circ} \mathrm{C}$ peak heating [31], as well as minimizing the cumulative exceedance of $350 \mathrm{ppm}$, indicative for the damage on Earth systems due to excess radiative forcing. Section 5 outlines the implications of such physically constraint pathways for society.

\section{Method}

The scope of this analysis is to explore the energy frontiers for transitioning to a fully renewable energy system and cleaning up the atmosphere from $\mathrm{CO}_{2}$ in excess of $350 \mathrm{ppm}$ on a global scale and with a time frame from 2022 until 2100. All renewable energy converters other than direct solar are currently close to or already beyond their sustainable potential within Earth system boundaries [37]. Even though other renewables (in particular wind) may provide a significant contribution on the local scale, only solar has a large enough potential to fully replace fossil fuels globally $[31,37,50]$. Consequently, direct solar energy conversion on the already sealed surface of the built environment is considered the sole technology for new RE installations. The present renewable energy system, currently supplying $1.07 \mathrm{TW}$ primarily through hydropower and biomass [51], is assumed not to change in the future and excluded.

\footnotetext{
${ }_{1}$ https://www.climateinteractive.org/tools/c-roads/
} 
Constraints other than energy and sustainable RE potentials within Earth system boundaries, such as material availability, manpower or finance, are omitted to allow finding the energy frontiers. Spatial variations, e. g. local solar resource potentials, are combined to global totals. Daily and seasonal variations are not explicitly modeled, but considered through the demand for storage [32], defined as exogenous parameters (SectionS1.2). The technical and social feasibility of a chosen storage demand has to be evaluated with a spatially and temporally refined model (e.g. [52]) and is outside the scope of this research.

The effect of the energy transition and atmospheric clean-up on the climate is evaluated through net cumulative $\mathrm{CO}_{2}$ emissions to the atmosphere and upper oceans. Peak net cumulative $\mathrm{CO}_{2}$ emissions thereby correspond with the probability to exceed $1.5^{\circ} \mathrm{C}$ peak heating [22, 31]. Furthermore, $350 \mathrm{ppm}$ can be expressed as cumulative $\mathrm{CO}_{2}$ emissions remaining in atmosphere and upper oceans. For returning to $350 \mathrm{ppm}$ as much $\mathrm{CO}_{2}$ has to be removed as had been emitted since 1988, when it had been passed the first time [53, 54]. As this research targets the fastest possible transformation of the energy system, we set other greenhouse gas emissions (e. g. $\mathrm{CH}_{4}, \mathrm{~N}_{2} \mathrm{O}$ ) and land use related $\mathrm{CO}_{2}$ emissions to net zero for simplicity. Subsequent research will need to show the energetic implications and dynamics for mitigating non-energy related emissions.

Meeting the scope of this research, the "3-machines" model (Section 3) is built on energy and $\mathrm{CO}_{2}$ balances, using the fundamental physical laws of conservation of energy and matter, and reduced to the essential system elements representing the energy system supplying humanity's power demand linked to the carbon cycle. It is a system-dynamics (SD) model, i. e. a system of coupled ordinary differential equations (ODE). State variables represent energy stocks (box model), i. e. the system's elements, which are linked with first derivatives (energy fluxes) representing power. The trajectories of the system are calculated by numerically solving the coupled ODE for consecutive time steps for different parameter sets defining scenarios (simulations Section 4). SD is an established method to operationalize such a model and a number of software tools are readily available. The "3-machines" energy transition model is implemented in "InsightMaker" [55], a freely-available, browser-based system dynamics (SD) application"

The energy system is represented as three point size machines, where spacial variations are reduced to global averages (Section 3.1). Electric energy is used as the universal currency for energy, i. e. all energy and power values are converted to electric energy equivalents [31,37], which is pure exergy convertible into any other form of energy. Most renewable energy technologies, in particular solar PV, produce electricity [37]. Each of the three machines (fossil engine, solar engine and carbon scrubber) is defined through the stock of embodied energy, which can increase through new installations (i. e. embodied energy investments) and decrease when reaching end-of-life. This allows both to analyse the dynamic of the transition itself but also the subsequent replacement cycles. Technical developments in embodied energy investments - as had been observed in the past for PV $[56,57]$ and is expected, yet not well studied, for other key technologies [32] - are uncertain in the future, especially when considering extremely fast transitions [32]. While learning in embodied energy can be included, it is disregarded in this first version of the model. The energy system is linked to the carbon cycle through positive and negative $\mathrm{CO}_{2}$ emissions (Section $\mathrm{S} 4$ ). The system minimises the supply gap between power demand of society and power supply by the energy system (system controller Section S3).

The model is presented in detail in Section 3 and in the supplementary materials. It was validated with structural and behavioral validation tests [58] (Section S6) and used to explore an evolution of scenarios from fossil baseline with continued growth of fossil emissions to reaching $350 \mathrm{ppm}$ well before the end of this century (Section 4 and S5). The aim of the scenarios is to test the influence of key system parameters (e. g. energy demand Section S2) and find transformations that both minimize peak cumulative $\mathrm{CO}_{2}$ emissions and cumulative exceedance of $350 \mathrm{ppm}$.

\section{Model description}

The three "machines" in the model are: a fossil engine (fC) and a solar engine (PV) both feeding and drawing power to and from the grid with the purpose of supplying society's annual average power demand as well as a carbon scrubber (CCS) removing and sequestering $\mathrm{CO}_{2}$. Together they constitute the energy system, which is coupled to an elementary carbon cycle and is controlled by a system controller (Fig. 1). ${ }^{2}$ The model can be accessed here: https://insightmaker.com/insight/2swt92w2TnkTv37vM97BZX/3-machines-release1.
Note: Insightmaker is a tool for both SD and agend based modelling (ABM). The model uses the SD functionality only. 


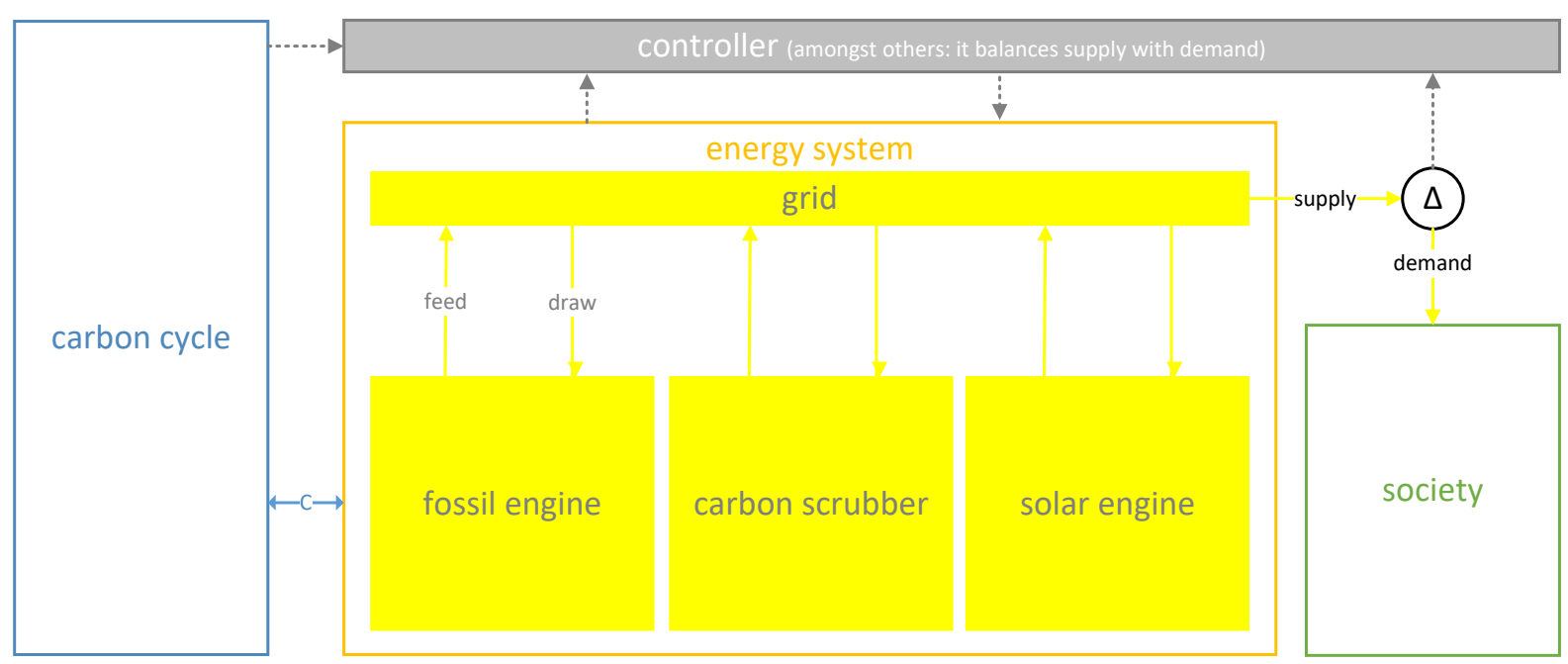

Figure 1: Overview of the 3-machines energy transition model. Dashed arrows are information flows, solid arrows are power or $\mathrm{CO}_{2}$ flows. The controller dynamically matches the supply with the demand by measuring their difference $\Delta$ and adjusting the various power flows in the energy system according predefined rules.

\subsection{Energy system}

The fossil engine (fC, Section S1.1) combines all current non-renewable energy conversion technologies (i. e. fossil, nuclear and waste) across all energy sectors (i. e. electricity, mobility and heat) into one single hypothetical thermal power plant producing electricity [31]. It converts fossil fuels into electric energy and emits $\mathrm{CO}_{2}$ at a constant emission intensity of $5.41 \mathrm{Gt} / \mathrm{TWa}$, which corresponds to today's emission intensity if all fossil fuels were converted to electricity. Fossil fuel shifts are not considered for simplicity. Initially, the fossil engine operates at a capacity factor $C F_{\mathrm{fC}, 0}=0.75$, supplying all of the non-renewable power demand.

The solar engine (PV, Section S1.2) combines all future PV installations and energy storage technologies (e.g. Li-ion batteries [59], hydro-pumped storage [60] or synthetic $\mathrm{CH}_{4}$ [61]) in a single hypothetical machine $[31,32]$. It converts insolation to electric energy with PV technologies and provides a part of the harvested power via storage. For simplicity, no other solar conversion technology (e.g. solar water heating or concentrated solar power) is considered [31]. PV installed on already sealed surface of the built environment can supply $21 \mathrm{TW}$ of annual average power [37]. Only if this is exhausted, additional surface as part of the solar potential in deserts may be utilized [37], which in the model can be specified as the desert potential fraction. Hence, the modelled transition doesn't require solar farms on green fields, wind parks or energy forests.

Energy storage allows to be independent from PV supply for a certain period of time, the independence time. A larger independence time slows the growth of the solar engine as energy is necessary to build storage. Storing a larger fraction $\phi$ of solar supply increases storage losses [32] (Section S1.2).

The third machine is a carbon scrubber (CCS, Section S1.3), which draws power from the grid to build its infrastructure and to capture and transfer $\mathrm{CO}_{2}$ to the lithosphere [62]. It is modelled as post-combustion capture for capturing parts of the emissions from the fossil engine exhaust with a capture efficiency of $90 \%$ [63-65]. It is assumed that $50 \%$ of emissions are generated at stacks where post-combustion is feasible (e.g. power plants, industrial point sources). Furthermore, CCS is modelled as direct air capture (DAC) [66-72], which removes $\mathrm{CO}_{2}$ directly from the atmosphere. Post-combustion CCS is energetically less expensive to operate $\left(E I_{\mathrm{pcCCS}}=0.06 \mathrm{TWa} / \mathrm{Gt}[73,74]\right)$ than DAC $\left(E I_{\mathrm{DAC}}=0.2 \mathrm{TWa} / \mathrm{Gt}\right.$ Section S1.3 $)$, while the embodied energy is approximately the same $(E I T=0.25$ a Section S1.3). Other negative emission pathways (e.g. reforestation, biochar in soils, bioenergy with carbon capture and storage [75]) are not considered as they may conflict food security and biodiversity when deployed at large scale and depend on agricultural production factors, many of which are already beyond their sustainable limit [12]. In contrast, resource requirements for DAC [72] are not critical and it can be scaled limited only by energy [76]. If powered by the fossil engine, CCS can be operated up to the full installed capacity. Powering DAC 
through the solar engine, in contrast, requires either to build and operate storage or it is operated directly from local solar supply. In the latter case, the capacity factor of CCS is restricted to $C F_{\mathrm{CCS}} \leq 0.32$ and CCS overcapacity has to be built. When optimizing for lowest total power demand, CCS is best operated directly through the solar engine (Section S1.3.1). The second best option is to operate CCS through batteries at constant load, however, material requirements for batteries are much more critical [33, 34] than for building DAC overcapacity [72]. Consequently, building DAC overcapacity is not only optimal from an energy but also material perspective. This is, however, in contrast to an economic optimisation, which favors operating DAC near base load [77].

\subsection{Power demand}

The power demand of society (Section S2) can be changed over time either at fixed growth rates or by following population growth and gradually adjusting per capita demand to a specified target within a specified time (demand adjustment duration and demand adjustment delay time). Per capita targets can be set, for example, to decent living energy (DLE, $\approx 300 \mathrm{w} /$ person) [78], low energy demand (LED, $\approx 680 \mathrm{~W} /$ person) [29] or the 2000-watt-society [79]. Global population forecasts can be considered with a chosen confidence $(2.5 \%, 10 \%, 50 \%, 90 \%$ and $97.5 \%$ ) according to UN world population prospects 2019 [80].

In 2018, global final power demand in electric energy equivalents was $7.1 \mathrm{TW}(932 \mathrm{~W} /$ person, with renewable energy (RE) contributing $1.04 \mathrm{TW}$ [31, 51, 81, 82]. The current renewable energy system is assumed to remain constant and not contributing to the transition. Assuming constant per capita demand from 2018 till 2022, the initial demand supplied by the current non-renewable energy system of $P_{\text {demand }, 0}=6.3 \mathrm{TW}$.

\subsection{System controller}

The system controller matches supply with demand. It measures the difference between supply and demand (i. e. supply gap) and adjusts the capacity factors $(\mathrm{CF})$ of the fossil and/or solar engine accordingly (Section S3). CF is defined here as the fraction of the maximum output power of installed capacity actually supplied $^{3}$. CF can range between $C F \in[0,1]$. In certain simulation runs, supply collapses irrecoverably, e.g. when there is not enough power available to maintain the required installed capacity. The system controller also governs the power invested for building and replacing installed capacity of all three machines as well as for operating CCS. Energy investments provided by the fossil engine can be controlled with the fossil investment factor $\beta \in[0,1]$, describing the fraction of the maximally available idle capacity to be invested. During the transition, the solar engine can grow with its own supply or it can replace fossil output, which is adjusted with the fossil replacement factor $\alpha \in[0,1]$. Power is allocated first to satisfy society's demand, second to maintain the fossil engine's installed capacity during the transition, third to build and maintain the solar engine and last to build, operate and maintain CCS.

Smaller time steps improve the quality of the control, as the controller can react faster to changes in the system. Transients shorter than $<1$ a are artefacts of the simulation and have no direct translation to the real world.

\subsection{Carbon cycle}

The energy system is linked to a elementary carbon cycle (Section S4). The operation of the fossil engine releases $\mathrm{CO}_{2}$ from the lithosphere to the atmosphere. Part of these emissions are absorbed by upper oceans within a short time $[83,84]$ and are released back in the event of falling atmospheric $\mathrm{CO}_{2}$ concentrations [53]. The carbon transfer to the deep ocean is slow compared to the time period of interest for this study and thus omitted. This behaviour is modelled with a combined $\mathrm{CO}_{2}$ stock for the atmosphere and upper oceans. $\mathrm{CO}_{2}$ is removed to the lithosphere through (i) a constant natural leak (i. e. sedimentation and weathering) of $0.8 \mathrm{Gt} / \mathrm{a}[84-86]$ and (ii) CCS.

\footnotetext{
${ }^{3}$ For solar PV, capacity factors are often provided in regard to nameplate capacity ("peak" power), however, the maximum output capacity is lower and depends on the location. Nominal capacity of PV is the maximum annual energy supply, i. e. without curtailment.
} 


\section{Simulation experiments}

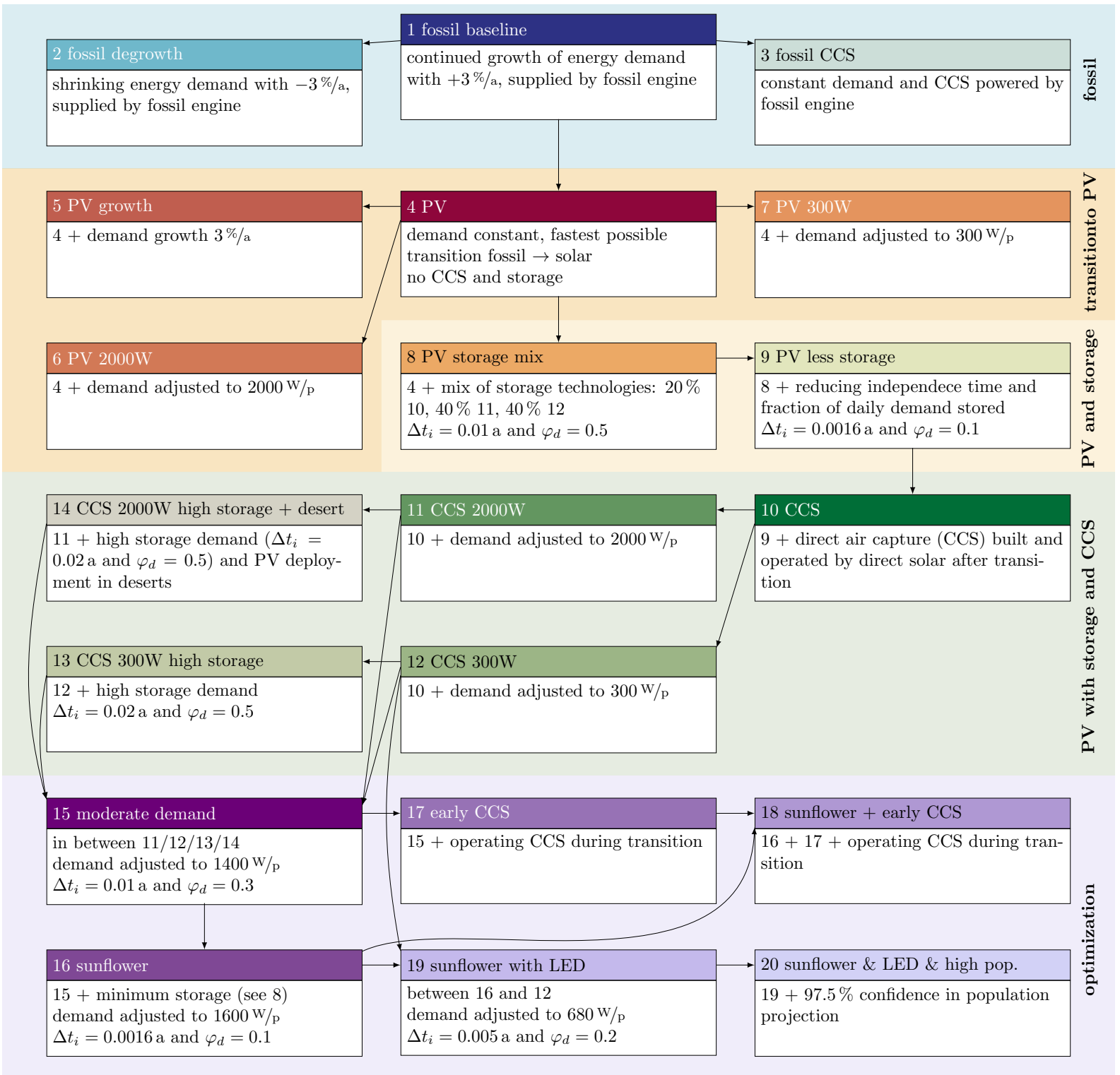

Figure 2: Evolution of simulation experiments: a graphical overview of dependencies (inheritance indicated by "number+"). See also Fig. S16.

Using the 3-machines energy transition model, various pathways are evolved (Fig. 2), exploring narratives ranging from "continued fossil growth" to "reaching $350 \mathrm{ppm}$ before the end of this century". Pathways are evaluated against peak cumulative $\mathrm{CO}_{2}$ emissions, which correlate with induced peak heating [22], as well as against cumulative exceedance of $350 \mathrm{ppm}$ throughout the simulation period, which can be seen as a proxy for the climate-induced pressure on ecosystems. All simulation experiments cover the time period beginning of 2022 until beginning of 2100 (i.e. 78 a), to test if the climate could be stabilized before the end of this century $[7,13,87]$. The integration time step is chosen $0.1 \mathrm{a}$.

Starting with (1) fossil baseline, energy demand grows exponentially at a growth rate of $3 \%$ per year (Fig. 4). It increases more than five-fold and reaches over $33 \mathrm{TW}$ in 2100 . This demand is satisfied by the fossil engine alone, requiring it to grow together with demand. As a consequence, cumulative $\mathrm{CO}_{2}$ emissions grow exponentially, reaching almost $10000 \mathrm{Gt}$ in 2100 and surpassing $1.5^{\circ} \mathrm{C}$ with $50 \%$ confidence within 10 a (Fig. 3).

Testing the capabilities of the fossil engine, energy demand shrinks in scenario (2) fossil degrowth. This is to answer the question: "Is demand reduction alone effective in reaching climate targets?" Reducing 


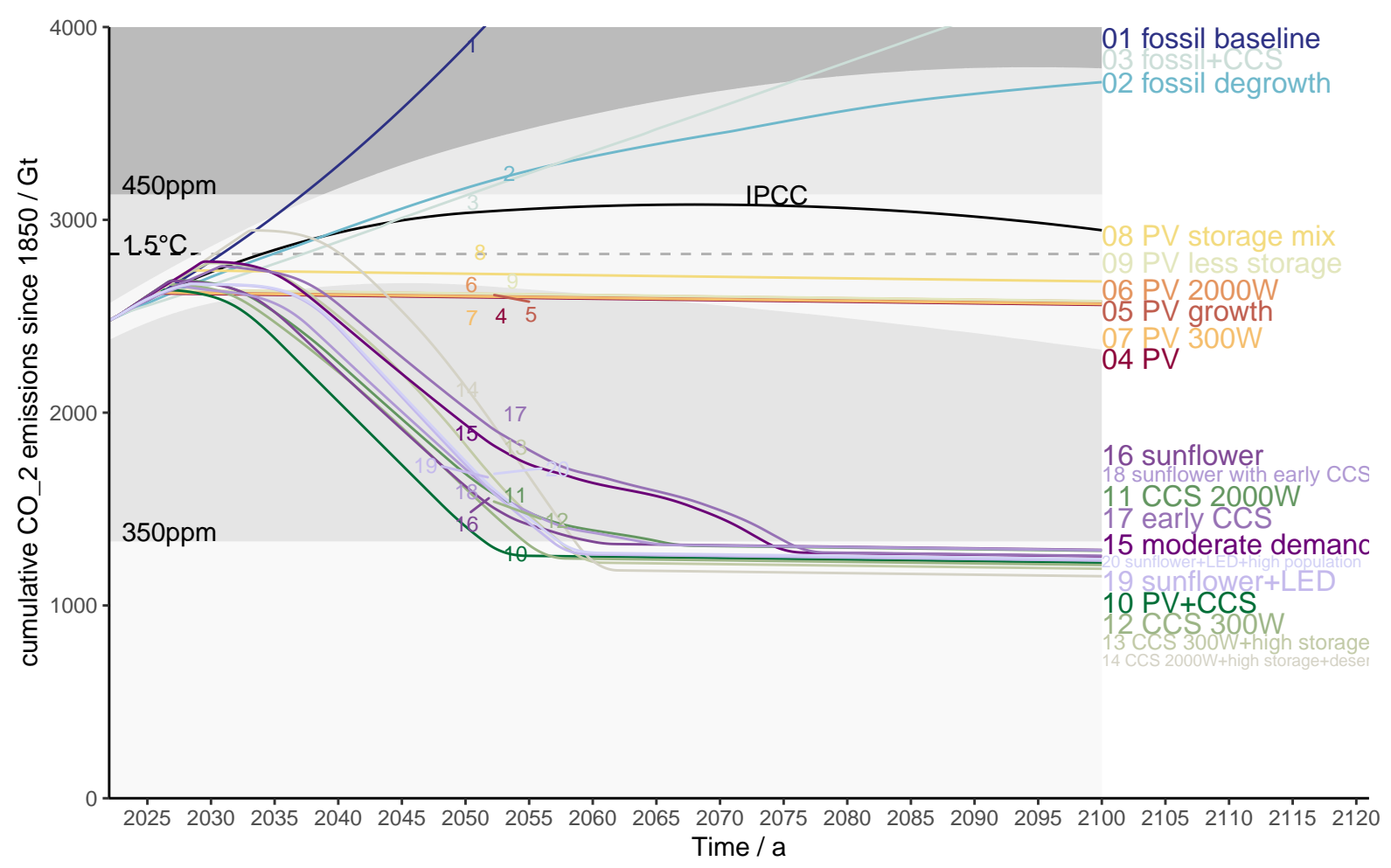

Figure 3: Cumulative $\mathrm{CO}_{2}$ emissions since 1850 over the simulation period (2022 to 2100). Cumulative emissions correlating with $350 \mathrm{ppm}$ and $450 \mathrm{ppm}$, as well as $1.5^{\circ} \mathrm{C}$ heating with $50 \%$ probability are shown as horizontal lines. The range of IPCC scenarios targeting $1.5^{\circ} \mathrm{C}$ and $2{ }^{\circ} \mathrm{C}$ heating is indicated with the solid black line (mean) and the shaded light grey area (most ambitious and least ambitious pathways) [24]. For scenario descriptions (colored lines), refer to the text.

demand exponentially by $-3 \% /$ a, shrinks the demand to $1 / 5$ or $1.9 \mathrm{TW}$ in 2100 (i. e. about $200 \mathrm{w} / \mathrm{p}$, which is below minimal energy requirements per person for a decent life [78]). Still, cumulative $\mathrm{CO}_{2}$ emissions rise to almost $3700 \mathrm{Gt}$ in 2100 , surpassing $1.5^{\circ} \mathrm{C}$ with $50 \%$ around 2037. Even when sacrificing a decent life, shrinking fossil demand alone is insufficient to stabilize the climate.

In scenario (3) fossil CCS, energy demand is held constant and a carbon scrubber is added to the fossil engine. It still leads to an almost linear growth of cumulative $\mathrm{CO}_{2}$ emissions (Fig. 3) because building and operating the carbon scrubber requires additional power. This power has to be provided by the fossil engine, increasing $\mathrm{CO}_{2}$ emissions and canceling negative emissions to a large extent. Scenarios (1) - (3) show that the fossil engine alone is neither able to comply with the $1.5^{\circ} \mathrm{C}$ nor with the $350 \mathrm{ppm}$ goal, confirming that fossil fuels cannot have a future.

Switching off the fossil engine immediately, however, would collapse power supply, as today's renewable energy system is not yet capable to replace it. Consequently, the fossil engine is necessary for the construction of the new solar engine. Scenario (4) $P V$ aims to find the fastest possible transition, replacing the fossil with the solar engine. Demand is kept constant and CCS as well as energy storage are excluded. Maximum fossil investment and no fossil replacement during the transition [31] results in the fastest possible transition. Transition completes within 4 a and exceeds $1.5{ }^{\circ} \mathrm{C}$ global heating [22] with $8 \%$ probability (Tab. S5). Because all PV panels have similar and narrowly distributed lifetimes [50], they have to be replaced about the same time after the transition completed. This leads to repeating replacement cycles, which necessitate to build overcapacity of the solar engine.

An exponentially growing energy demand during and after the transition, scenario (5) $P V$ growth, is feasible until about 2080. Thereafter supply collapses (Fig. 4) if solar PV capacity is restricted to the already built environment. The same limit is reached for a global $2000 \mathrm{~W}$ society (6) PV 2000W). However, extending PV installations to desert areas could prevent supply collapse when demand approaches $21 \mathrm{TW}$. Growing demand during the transition prolongs transition time, as less power is available to build solar capacity and the fossil engine needs to be grown in addition. Consequently, this increases cumulative $\mathrm{CO}_{2}$ 


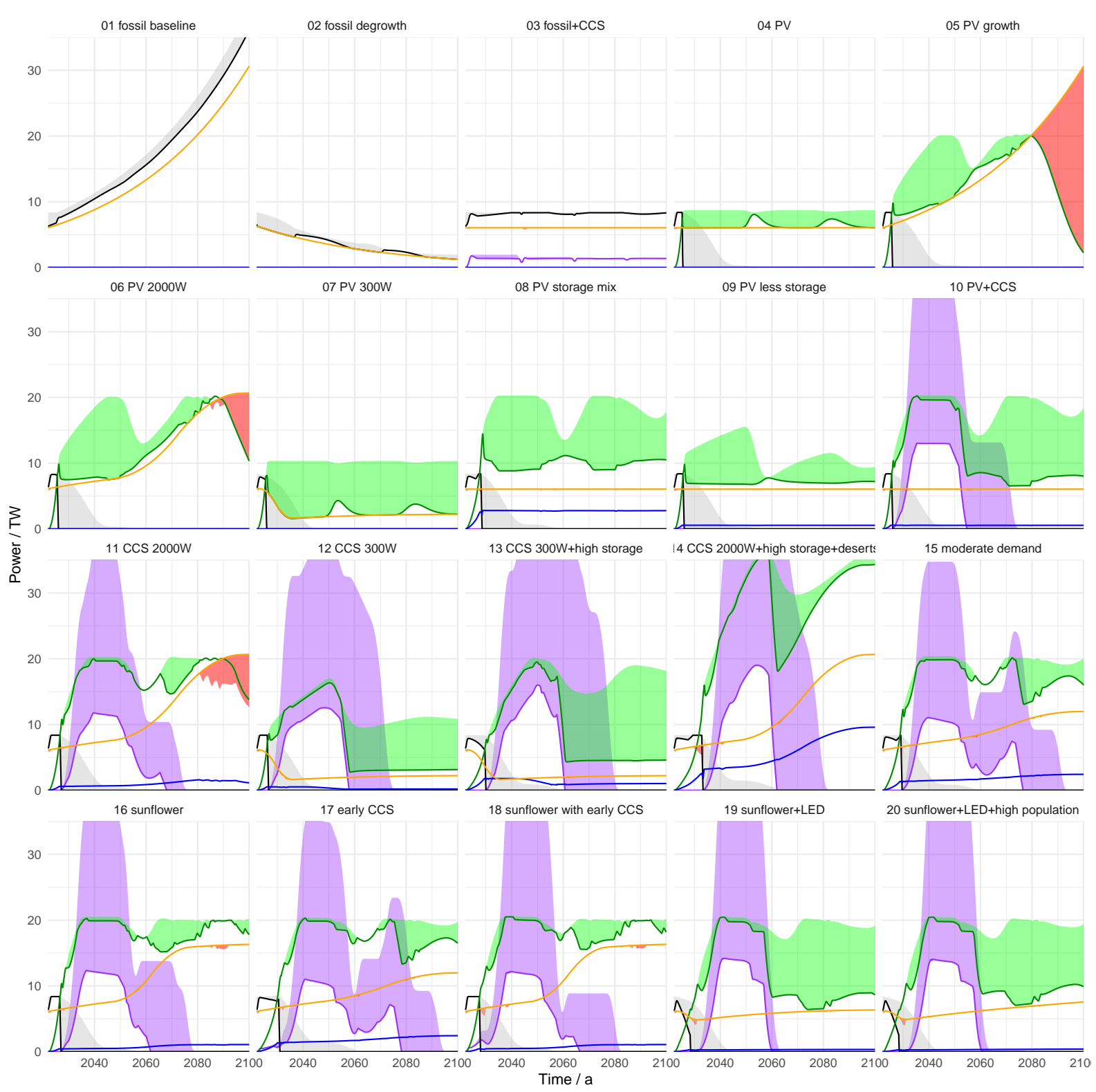

Figure 4: Power diagrams for each scenario. For a description of scenarios, see text. Lines show the output for a machine and shaded areas the idle capacity for each machine: fossil engine (grey), solar engine (green) with storage losses (blue) and CCS (purple). Orange line indicates the demand from society and red shaded areas show shortages in supply, i.e. when supply falls below demand. 


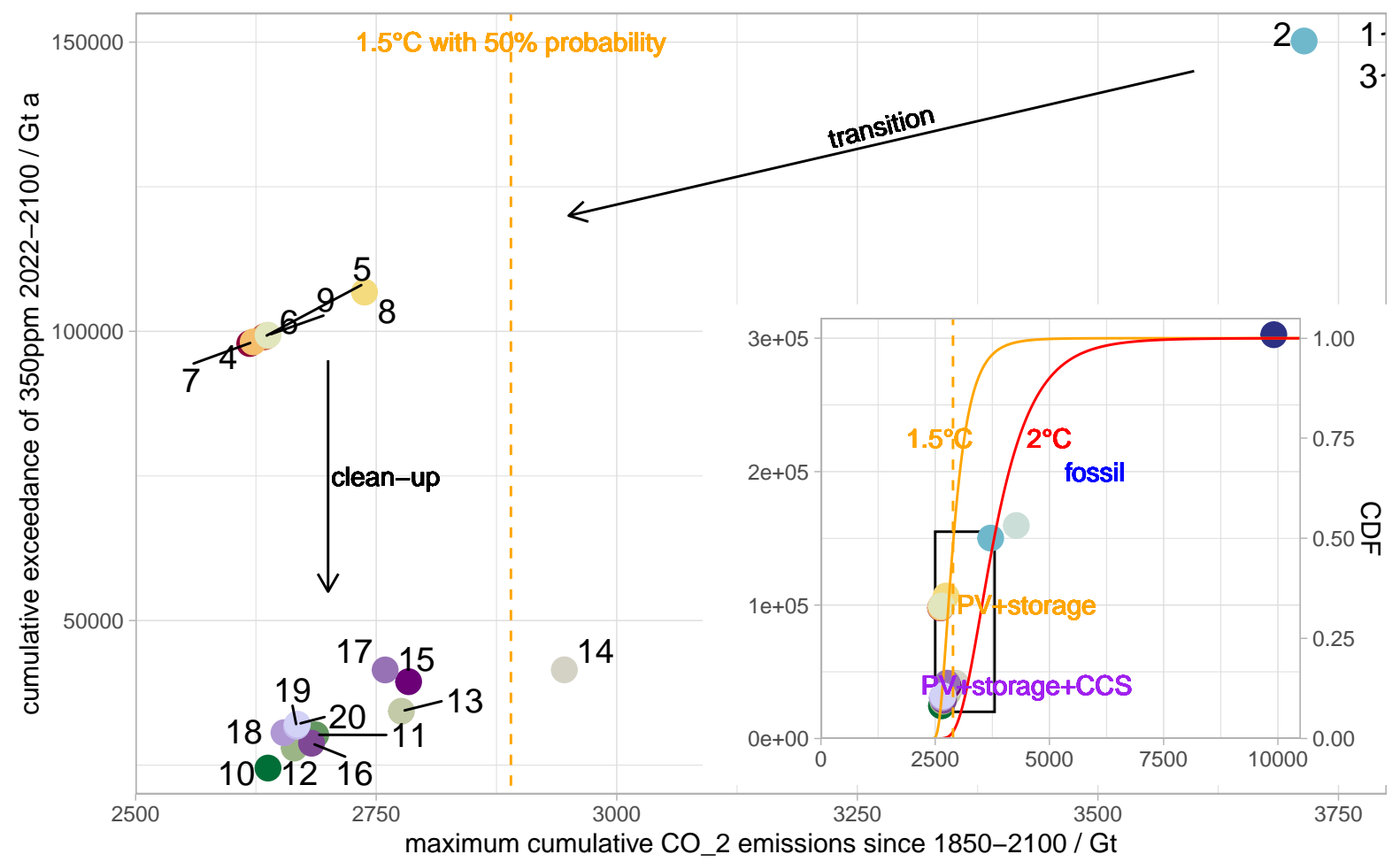

Figure 5: Maximum cumulative $\mathrm{CO}_{2}$ emissions from 2022 until 2100 vs. cumulative exceedance of $350 \mathrm{ppm}$ from 2022 until 2100. Inlay (right bottom) shows the whole range of results and the cumulative distribution function (CDF, right axis) of the probability to violate $1.5^{\circ} \mathrm{C}$ (orange) and $2{ }^{\circ} \mathrm{C}$ (red) peak heating [22]. Fossil scenarios (blue) are the highest, transition scenarios from fossil to PV with and without storage (orange) show similarly low cumulative emissions as scenarios including CCS (purple and green). The latter have significantly lower cumulative exceedance. The optimum scenario is (17) CCS with $300 \mathrm{w} / \mathrm{p}$ (lower left corner). Fig. S18 shows the same data for probability to exceed $1.5^{\circ} \mathrm{C}$ global heating [22] over cumulative exceedance of $350 \mathrm{ppm}$. Numerical results are provided in Tab. S5.

emissions (Fig. 5).

In scenario (7) $P V 300 \mathrm{~W}$, per capita demand is reduced within 14 a from today's $930 \mathrm{w} / \mathrm{p}$ to $300 \mathrm{w} / \mathrm{p}$, which is considered the minimal average power required for a decent life [78]. The resulting transition is slightly faster, reducing cumulative emissions and the probability to exceed $1.5{ }^{\circ} \mathrm{C}$ to $5 \%$. The effect on the climate is small, because the transition completes before most of the demand reduction is realized.

Even though global insolation is constant, the local irradiance is not. Therefore, energy storage is a needed to smooth daily and seasonal solar and weather patterns [32]. Due to the considerable energetic costs of storage, demand for it is decisive for the energy transition [32, 88, 89]. In scenario (8) $P V$ storage, storage with an independence time of 0.01 a (half a week) and providing $\phi=0.5$ of daily demand through storage is added to scenario PV (4). Storage is provided as a mix of the three storage technologies: lithium-ion battery (electro-chemical) and pumped-hydro storage (mechanical) cover $40 \%$ each, while synthetic methane (chemical) covers the remaining $20 \%$. This scenario exceeds $1.5^{\circ} \mathrm{C}$ with $25 \%$ probability, highlighting the strong influence storage has on the transition [32].

Consequently, reducing both storage capacity and amount of stored energy has a profound effect on the transition [32]. In scenario (9) $P V$ less storage, independence time is reduced to $\Delta t_{i}=0.0016 \mathrm{a}=14.5 \mathrm{~h}$, which is minimally necessary to level out daily variations in solar supply and the fraction of daily demand stored is reduced to $\phi_{d}=0.1$, aligning most of society's demand with solar supply [32]. This reduces the probability to exceed $1.5{ }^{\circ} \mathrm{C}$ to $10 \%$, close to the fastest transition without storage (4) $P V$ ).

The scenarios (4) to (9) show that fast and complete transitions can limit global heating to below $1.5{ }^{\circ} \mathrm{C}$ with a confidence $>50 \%[31,32]$. This requires to increase the output of the fossil engine to grow the 
solar engine. The size and type of storage is essential: less storage is better for the climate [32]. Yet, a transition to a fossil-free society alone cannot return the atmospheric $\mathrm{CO}_{2}$ concentration to below $350 \mathrm{ppm}$ within this century. This requires to build and operate the carbon scrubber (CCS).

In scenario (10) CCS, CCS is built and operated with idle solar PV capacity after the transition (9) is completed. Thus, it has no effect on the transition itself and therefore also no effect on peak cumulative $\mathrm{CO}_{2}$ emissions. To avoid additional energy storage, CCS is only allowed to operate with solar power directly, thus limiting the capacity factor of the carbon scrubber to $C F_{\mathrm{CCS}} \leq 0.32$ (Section 3 and S1.3.1). This requires more CCS capacity (see purple area in Fig. 4), however, this is energetically cheaper than additional storage (Section S1.3.1). After the transition is completed, the solar engine is kept growing until its capacity reaches the limited area of the built environment. The resulting overcapacity is used to build and operate CCS so that the clean-up can be completed before the first replacement cycle of the solar engine around 2050. After the clean-up is completed, overcapacity may be maintained (green area in Fig. 4) to increase demand and storage.

When adjusting demand to $2000 \mathrm{w} / \mathrm{p}$ (11) CCS $2000 \mathrm{~W}$ ), the clean-up takes more than a decade longer, because there is less power available. Cumulative exceedance is $23 \%$ higher than when demand remains constant 10 (Fig. 5 and Tab. S5). When adjusting demand to $300 \mathrm{w} / \mathrm{p}$ (12) CCS $300 \mathrm{~W}$ ), solar capacity does not have to be built to its limit, which helps to preserve resources, as more power is available for CCS and clean-up can still be completed in 2054. Increasing the demand for storage in a $300 \mathrm{w} / \mathrm{p}$ society (13) $C C S 300 \mathrm{~W} S+)$ to $\Delta t_{i}=0.02$ a, i. e. one week, and $\phi_{d}=0.5$, increases the probability to exceed $1.5^{\circ} \mathrm{C}$ to $31 \%$ and cumulative exceedance by $40 \%$ relative to (10. In contrast, a $2000 \mathrm{w} / \mathrm{p}$ society with high storage and using $20 \%$ of deserts' PV potential (19) CCS $2000 \mathrm{~W} S+P V+$ ) will exceed $1.5^{\circ} \mathrm{C}$ heating with $56 \%$ probability and increase cumulative exceedance by $70 \%$ relative to (10). Although developing $\mathrm{PV}$ in deserts is challenging for many reasons [90-92], it cannot fundamentally change the dynamics of the transition. High energy demand above $1600 \mathrm{~W}$ per capita become possible, yet it cannot reduce the probability to exceed $1.5{ }^{\circ} \mathrm{C}$ peak heating. The clean-up may be accelerated only if energy demand is constant or shrinking. Therefore, PV in deserts is excluded in the following scenarios.

Power demand per person can still increase to $1400 \mathrm{w} / \mathrm{p}$ (15) moderate demand) at moderate storage of $\Delta t_{i}=0.01$ a and $\phi=0.3$, which, however, delays the clean-up until 2073. Consequently, the probability to exceed $1.5{ }^{\circ} \mathrm{C}$ is $32 \%$ and cumulative exceedance increases by $60 \%$ relative to (10). Reducing storage demand to $\Delta t_{i}=0.0016$ a and $\phi_{d}=0.1$ in scenario (16) sunflower, reduces the probability to exceed $1.5^{\circ} \mathrm{C}$ to $16 \%$, while cumulative exceedance increases only by $17 \%$ relative to 10 , even though energy demand can be increased to $1600 \mathrm{~W} / \mathrm{p}$ (Fig. 5). Aligning energy demand with solar supply in order to minimize the demand for storage is an effective strategy to improve climate protection as well as increase energy demand.

Instead of performing the clean-up as a subsequent step to the transition, it is also possible to start CCS in parallel to the transition (17) early $C C S$ ). For simplicity, post-combustion capture can be deployed during the transition, even though in reality, this CCS infrastructure would need to be adapted or rebuilt as DAC after the transition ended. Despite this simplification in favor of early CCS, it increases both cumulative exceedance (70\% above (10)) and cumulative emissions increasing the probability to exceed $1.5^{\circ} \mathrm{C}$ to $28 \%$ (Fig. 5). Combining sunflower (16) with early CCS (18) sunflower with early CCS) also leads to lower probability to exceed $1.5^{\circ} \mathrm{C}$ of $12 \%$, yet higher cumulative exceedance by $25 \%$ compared to 10 than when CCS starts after the transition (16). This shows that CCS shall only be operated after the transition is completed.

Finally, we define scenario (19) sunflower $L E D$, which aims at a power demand per person of $680 \mathrm{w} / \mathrm{p}$, proposed as a low energy demand (LED) scenario by Grubler et al. [29]. Storage independence time is set to two days $\left(\Delta t_{i}=0.005\right.$ a, while $20 \%$ of power is provided through storage. Part of the fossil output is replaced already during the transition, which allows for a smoother phase out of the fossil engine. This leads to a similar climate performance than sunflower (16) (Fig. 5) with lower energy demand per person but higher energy storage. Considering population prospects with $97.5 \%$ confidence [80] (20) sunflower LED pop+), the results are very similar to scenario (19). This is due to the fact that the population uncertainty is small in the near future when both the transition and the clean-up take place.

\section{Conclusion}

In this article, we presented the 3-machines energy transition model designed to find the energy frontiers for the energy transition and clean-up excess $\mathrm{CO}_{2}$. As shown by the various simulation experiments, 
stabilising the climate through limiting global heating to $1.5^{\circ} \mathrm{C}$ with $>50 \%$ probability and reducing atmospheric $\mathrm{CO}_{2}$ concentration below $350 \mathrm{ppm}$ remains still possible within this century, at least from an energy perspective. This, however, requires a novel strategy: first increasing fossil emissions to the maximum capacity of the fossil engine with the sole purpose of building solar capacity fastest; and second, switch off the fossil energy system as soon as the solar engine is big enough and power DAC at a massive scale to return to $350 \mathrm{ppm}$ soonest. In contrast to most proposed pathways, CCS is not part of the transition, but a major activity for the subsequent clean-up phase. During both phases of the transformation, energy demand and demand for storage needs to be as low as possible, following the idea of a sunflower society, aligning demand with solar supply [32]. Though possible, this would require a fundamental rethinking of our society:

Reduce energy demand per person. The higher the global average energy demand per person, the more difficult it gets to manage the transition within the constraints of the Earth system. Lowering the energy demand below today's average helps for the clean-up but not much for the transition itself. Furthermore, it is limited by the minimum energy demand for a decent life [78, 93, 94]. Energy demand per person shall ideally reduce to somewhere around $600 \mathrm{~W} / \mathrm{p}$ until the clean-up of $\mathrm{CO}_{2}$ in the atmosphere is completed. Afterwards it may safely increase. Today, energy demand is distributed unequally across the globe. Therefore, individuals and countries with a high energy demand have the moral imperative to reduce most (e.g. by a factor of ten for the average Swiss citizen), allowing those living in energy poverty today [94] to increase energy use up to this new global average. In conclusion, energy demand should be reduced as much as possible during the transition and clean-up, with the prospect of increasing energy supply significantly once the climate is stabilized.

Minimize energy storage. Storage is the second critical driver in the system, as it influences both the attainable speed of the transition as well as the necessary overcapacity of PV to provide for storage losses [32]. Independence times beyond three days seem unattainable during the task of stabilizing the climate. Synthetic fuels may play only a minor role as a storage technology due to their low round-trip efficiency. Individual motorized transport, air traffic and shipping powered by combustion of synthetic fuels may at best be continued at much reduced levels. Again, after the climate is stabilized, energy storage may safely increase, adding convenience in society. However, during the transition and carbon removal, society will need to align energy demand to renewable supply to minimize the demand for storage, i. e. implement a sunflower society [32].

Massive negative emissions. $\mathrm{CCS}$ is inevitable for removing excess $\mathrm{CO}_{2}$ from the atmosphere. From a climate perspective, however, its operation only makes sense when powered with solar energy. Otherwise, removed $\mathrm{CO}_{2}$ is offset by the increased fossil emissions resulting from the increased power output of the fossil engine and the energy transition slowed down. Hence, CCS needs to be powered directly with PV without energy storage when the transition is completed, as building CCS overcapacity is energetically less expensive than building and operating storage (Section S1.3.1, purple areas in Fig. 4).

No new fossils. Even though the fossil engine needs to operate at maximum capacity during the transition, no new fossil capacity needs to be installed. The currently installed capacity of the fossil engine is more than sufficient to power fast transitions. Consequently, there is no need to build any additional fossil capacity also not for fossil fuel shifts (e. g. from coal to gas). Still, in case of a gradual shut down (as in (13), (19) and (20), power plants with the lowest $\mathrm{CO}_{2}$ intensity should switch off last. Furthermore, the vast majority of proven fossil reserves need to stay in the ground [95], as the amount of fossil fuels required during the transition is in the order of seven to eight annual productions only [19] (Tab. S5).

Future research will need to investigate the energy implications of transforming other climate relevant sectors,e.g. agriculture, and new infrastructures due to demand changes, e. g. public transport, and thus their effect on the energy frontier for climate action. Beyond energy and greenhouse gases, the mobilisation of materials for building the necessary infrastructure, e. g. Ag in solar PV [96], may further limit the attainable speed of the transformation. The here proposed strategies will need to be investigated in more detailed models in order to validate and derive more concrete action plans (see Section S8).

To conclude, the simulation experiments show that much more ambitious transformation pathways are energetically possible than considered by IPCC. At least energetically, atmospheric $\mathrm{CO}_{2}$ concentration 
can be reduced to below $350 \mathrm{ppm}$ well before the end of this century. Yet, the probability to exceed $1.5^{\circ} \mathrm{C}$ global peak heating can no longer be kept below $5 \%$. This would be unacceptably high for other fields e. g. aircraft design or vaccine safety [31]. It seems all the more important to follow the most ambitious pathway, safeguarding the climate for future generations as best as we can. Bringing these transformations to life requires creating new visions and narratives collaboratively across the globe, portraying a desirable and equitable life with reduced energy demand, minimal storage, massive negative emissions and a fast and complete transition.

Declaration of Interest The authors declare that they have no known competing interests which could have appeared to influence the work reported in this paper.

\section{References}

1. World Meterological Organization. State of the Global Climate 2020 Report WMO-Nr. 1264 (WMO, 2021). https://library.wmo. int/doc_num.php?explnum_id=10618.

2. IPCC. Climate Change 2022 - Ipacts, Adaption and Vulerability Report (IPCC, 2022).

3. Lenton, T. M., Rockstrom, J., Gaffney, O., Rahmstorf, S., Richardson, K., Steffen, W. \& Schellnhuber, H. J. Climate tipping points too risky to bet against. Nature $\mathbf{5 7 5}$, 592-595. www. doi.org/10.1038/d41586019-03595-0 (2019).

4. Hoegh-Guldberg, O., Jacob, D., Taylor, M., Guillen Bolanos, T., Bindi, M., Brown, S., Camilloni, I. A., Diedhiou, A., Djalante, R., Ebi, K., Engelbrecht, F., Guiot, J., Hijioka, Y., Mehrotra, S., Hope, C. W., Payne, A. J., Portner, H. O.,

Seneviratne, S. I., Thomas, A., Warren, R. \& Zhou, G. The human imperative of stabilizing global climate change at 1.5 degrees C. Science 365, 1-11. www. doi .org/10.1126/science. aaw6974 (2019).

5. Steffen, W., Rockstrom, J., Richardson, K., Lenton, T. M., Folke, C., Liverman, D., Summerhayes, C. P., Barnosky, A. D., Cornell, S. E., Crucifix, M., Donges, J. F., Fetzer, I., Lade, S. J., Scheffer, M., Winkelmann, R. \& Schellnhuber, H. J. Trajectories of the Earth System in the Anthropocene. Proc Natl Acad Sci USA 115, 8252-8259. www . doi .org/10.1073/pnas . 1810141115 (2018).

6. Wunderling, N., Donges, J. F., Kurths, J. \& Winkelmann, R. Interacting tipping elements increase risk of climate domino effects under global warming. Earth System Dynamics 12, 601-619. www.doi.org/10.5194/esd-12-601-2021 (2021).

7. Hansen, J., Kharecha, P., Sato, M., Masson-Delmotte, V., Ackerman, F., Beerling, D. J., Hearty, P. J., Hoegh-Guldberg, O., Hsu, S. L., Parmesan, C., Rockstrom, J., Rohling, E. J., Sachs, J., Smith, P., Steffen, K., Van Susteren, L., von Schuckmann, K. \& Zachos, J. C. Assessing "dangerous climate change": required reduction of carbon emissions to protect young people, future generations and nature. PLoS One 8, e81648. www.doi.org/10.1371/journal.pone. 0081648 (2013).

8. Petit, J. R., Jouzel, J., Raynaud, D., Barkov, N. I., Barnola, J. M., Basile, I., Bender, M., Chappellaz, J., Davis, M., Delaygue, G., Delmotte, M., Kotlyakov, V. M., Legrand, M., Lipenkov, V. Y., Lorius, C., PÉpin, L., Ritz, C., Saltzman, E. \& Stievenard, M. Climate and atmospheric history of the past 420,000 years from the Vostok ice core, Antarctica. Nature 399, 429-436. www.doi.org/10.1038/20859 (1999).

9. Berger, A., Mesinger, F. \& Sijacki, D. Climate Change - Inferences from paleoclimate and regional aspects www. doi .org/10.1007/978-3-7091-09731 (Springer, 2012).

10. Foster, G. L., Royer, D. L. \& Lunt, D. J. Future climate forcing potentially without precedent in the last 420 million years. Nat Commun 8, 14845.

www.doi.org/10.1038/ncomms 14845 (2017).

11. Luthi, D., Le Floch, M., Bereiter, B., Blunier, T., Barnola, J. M., Siegenthaler, U., Raynaud, D., Jouzel, J., Fischer, H., Kawamura, K. \& Stocker, T. F. High-resolution carbon dioxide concentration record 650,000-800,000 years before present. Nature 453, 379-82. 
www.doi.org/10.1038/nature06949 (2008).

12. Steffen, W., Richardson, K., Rockstrom, J., Cornell, S. E., Fetzer, I., Bennett, E. M., Biggs, R., Carpenter, S. R., de Vries, W., de Wit, C. A., Folke, C., Gerten, D., Heinke, J., Mace, G. M., Persson, L. M., Ramanathan, V., Reyers, B. \& Sorlin, S. Sustainability. Planetary boundaries: guiding human development on a changing planet. Science 347, 1259855.

www.doi.org/10.1126/science. 1259855 (2015).

13. Center for Biological Diversity and 350.org. Not just a number: Achieving A CO2 Concentration of 350 ppm or Less To Avoid Catastrophic Climate Impacts Report (). https://www.biologicaldiversity.org/ programs/climate_law_institute/350_ or_bust/pdfs/Not_Just_a_Numberv3.pdf.

14. Friedlingstein, P., O'Sullivan, M., Jones, M. W., Andrew, R. M., Hauck, J., Olsen, A., Peters, G. P., Peters, W., Pongratz, J., Sitch, S., Le Quéré, C., Canadell, J. G., Ciais, P., Jackson, R. B., Alin, S., Aragão, L. E. O. C., Arneth, A., Arora, V., Bates, N. R., Becker, M., Benoit-Cattin, A., Bittig, H. C., Bopp, L., Bultan, S., Chandra, N., Chevallier, F., Chini, L. P., Evans, W., Florentie, L., Forster, P. M., Gasser, T., Gehlen, M., Gilfillan, D., Gkritzalis, T., Gregor, L., Gruber, N., Harris, I., Hartung, K., Haverd, V., Houghton, R. A., Ilyina, T., Jain, A. K., Joetzjer, E., Kadono, K., Kato, E., Kitidis, V., Korsbakken, J. I., Landschützer, P., Lefèvre, N., Lenton, A., Lienert, S., Liu, Z., Lombardozzi, D., Marland, G., Metzl, N., Munro, D. R., Nabel, J. E. M. S., Nakaoka, S.-I., Niwa, Y., O'Brien, K., Ono, T., Palmer, P. I., Pierrot, D., Poulter, B., Resplandy, L., Robertson, E., Rödenbeck, C., Schwinger, J., Séférian, R., Skjelvan, I., Smith, A. J. P., Sutton, A. J., Tanhua, T., Tans, P. P., Tian, H., Tilbrook, B., van der Werf, G., Vuichard, N., Walker, A. P., Wanninkhof, R., Watson, A. J., Willis, D., Wiltshire, A. J., Yuan, W., Yue, X. \& Zaehle, S. Global Carbon Budget 2020. Earth System Science Data 12, 3269-3340.

www . doi .org/10.5194/essd-12-32692020 (2020).

15. Le Quéré, C., Jackson, R. B., Jones, M. W., Smith, A. J. P., Abernethy, S.,
Andrew, R. M., De-Gol, A. J., Willis, D. R., Shan, Y., Canadell, J. G., Friedlingstein, P., Creutzig, F. \& Peters, G. P. Temporary reduction in daily global $\mathrm{CO} 2$ emissions during the COVID-19 forced confinement. Nature Climate Change 10, 647-653. www.doi.org/10.1038/s41558-020-0797$\mathrm{x}(2020)$.

16. IPCC. Climate Change 2022: Mitigation of Climate Change Report (IPCC, 2022). https://www.ipcc.ch/report/ar6/wg3/.

17. Dlugokencky, E. \& Tans, P. NOAA Trends in Atmospheric Carbon Dioxide Web Page. 2020. www. esrl.noaa.gov/gmd/ccgg/trends/.

18. International Renewable Energy Agency. Renewable capacity highlights Report (IRENA, 2020). https://www.irena.org/-/media/Files/ IRENA/Agency/Publication/2020/Mar/ IRENA_RE_Capacity_Highlights_2020. pdf?la=en\&hash= B6BDF8C3306D271327729B9F9C9AF5F1274FE30B]

19. British Petroleum (BP). Statistical Review of World Energy Web Page. 2020. https://www. bp.com/en/global/corporate/energyeconomics/statistical-review-ofworld-energy.html.

20. Climate action tracker. Climate action tracker thermometer Web Page. 2021. https://climateactiontracker .org/ global/cat-thermometer/.

21. Raftery, A. E., Zimmer, A., Frierson, D. M. W., Startz, R. \& Liu, P. Less Than 2 degrees C Warming by 2100 Unlikely. Nat Clim Chang 7, 637-641. www.doi.org/10.1038/nclimate3352 (2017).

22. IPCC. Sixth Assessment Report: Physical Science Basis Report (IPCC, 2021). https://www.ipcc.ch/report/sixthassessment-report-working-group-i/.

23. SEI and IISD and ODI and E3G and UNEP. Production gap report Report (2021). https: //productiongap.org/2021report/.

24. IPCC. Global Warming of 1.5 degree C. An IPCC Special Report on the impacts of global warming of 1.5 degree $C$ above pre-industrial levels and related global greenhouse gas emission pathways, in the context of strengthening the global response to the threat of climate change, sustainable development, and efforts to eradicate poverty Report (Intergovernmental Panel for Climate Change, 2018). 
25. International Energy Agency. World Energy Outlook Report (International Energy Agency, 2019). www .doi.org/10.1787/20725302.

26. United Nations Environment Programme. Emissions gap report 2020 Report ISBN: 978-92-807-3812-4 (United Nations Environment Programme, 2020). https://www . unep.org/emissions-gapreport-2020.

27. Anderson, K. \& Peters, G. The trouble with negative emissions. Science 354, 182-183. www. doi .org/10.1126/science . aah4567 (2016).

28. Van Vuuren, D. P., Stehfest, E., Gernaat, D. E. H. J., van den Berg, M., Bijl, D. L., de Boer, H. S., Daioglou, V., Doelman, J. C., Edelenbosch, O. Y., Harmsen, M., Hof, A. F. \& van Sluisveld, M. A. E. Alternative pathways to the 1.5 degree celcius target reduce the need for negative emission technologies. Nature Climate Change 8, 391-397. www.doi .org/10.1038/s41558-018-01198 (2018).

29. Grubler, A., Wilson, C., Bento, N., Boza-Kiss, B., Krey, V., McCollum, D. L., Rao, N. D., Riahi, K., Rogelj, J., De Stercke, S., Cullen, J., Frank, S., Fricko, O., Guo, F., Gidden, M., Havlík, P., Huppmann, D., Kiesewetter, G., Rafaj, P., Schoepp, W. \& Valin, H. A low energy demand scenario for meeting the $1.5{ }^{\circ} \mathrm{C}$ target and sustainable development goals without negative emission technologies. Nature Energy 3, 515-527. www . doi .org/10.1038/s41560-018-01726 (2018).

30. Keysser, L. T. \& Lenzen, M. 1.5 degrees C degrowth scenarios suggest the need for new mitigation pathways. Nat Commun 12, 2676. www . doi .org/10.1038/s41467-021-228849 (2021).

31. Desing, H. \& Widmer, R. Reducing climate risks with fast and complete energy transitions: applying the precautionary principle to the Paris agreement. Environmental Research Letters 16. www .doi.org/10.1088/1748-9326/ac36f9 (2021).

32. Desing, H. \& Widmer, R. How much energy storage can we afford? On the need for a sunflower society, aligning demand with renewable supply. Biophysical Economics and Sustainability. www.doi.org/10.31219/osf .io/q6ywp (accepted).

33. Greim, P., Solomon, A. A. \& Breyer, C. Assessment of lithium criticality in the global energy transition and addressing policy gaps in transportation. Nat Commun 11, 4570. www . doi .org/10.1038/s41467-020-18402y $(2020)$.

34. Junne, T., Wulff, N., Breyer, C. \& Naegler, T. Critical materials in global low-carbon energy scenarios: The case for neodymium, dysprosium, lithium, and cobalt. Energy 211. www .doi.org/10.1016/j . energy.2020.118532 (2020).

35. IEA. The Role of Critical Minerals in Clean Energy Transitions Report (IEA, 2021). https://www.iea.org/reports/the-roleof-critical-minerals-in-clean-energytransitions.

36. European Commission. Critical Raw Materials for Strategic Technologies and Sectors in the EU - A Foresight Study Report (European Comission, 2020). https ://ec. europa.eu/docsroom/documents/42881.

37. Desing, H., Widmer, R., Beloin-Saint-Pierre, D., Hischier, R. \& Wäger, P. Powering a Sustainable and Circular Economy-An Engineering Approach to Estimating Renewable Energy Potentials within Earth System Boundaries. Energies 12, 1-18. www.doi.org/10.3390/en12244723 (2019).

38. Dupont, E., Koppelaar, R. \& Jeanmart, H. Global available solar energy under physical and energy return on investment constraints. Applied Energy 257. www.doi.org/10. 1016/j . apenergy.2019.113968 (2020).

39. Wilson, C., Kriegler, E., Van Vuuren, D. P., Guivarch, C., Frame, D. J., Krey, V., Osborn, T. J., Schwanitz, V. \& Thompson, E. Evaluating Process-Based Integrated Assessment Models of Climate Change Mitigation. IIASA Working paper WP-17-007. http://pure.iiasa.ac.at/ id/eprint/14502/1/WP-17-007.pdf (2017).

40. Anderson, K. Wrong tool for the job. Nature 573, 348 (2019).

41. Creutzig, F., Agoston, P., Goldschmidt, J. C., Luderer, G., Nemet, G. \& Pietzcker, R. C. The underestimated potential of solar energy to mitigate climate change. Nature Energy 2. www.doi .org/10.1038/nenergy . 2017.140 (2017). 
42. IIASA. The MESSAGEix framework Web Page. 2021.

https://docs.messageix.org/.

43. PBL and Utrecht University. IMAGE 3.2 Documentation Web Page. 2021. https: //models.pbl.nl/image/index.php/ Welcome_to_IMAGE_3.2_Documentation.

44. European Commission and Joint Research Centre and Keramidas, $\mathrm{K}$ and Kitous, $\mathrm{A}$ and Schade, B and Després, J and Schmitz, A. POLES-JRC model documentation : 2018 update www.doi.org/doi/10.2760/814959 (Publications Office, 2018).

45. Baumstark, L., Bauer, N., Benke, F., Bertram, C., Bi, S., Gong, C. C., Dietrich, J. P., Dirnaichner, A., Giannousakis, A., Hilaire, J., Klein, D., Koch, J., Leimbach, M., Levesque, A., Madeddu, S., Malik, A., Merfort, A., Merfort, L., Odenweller, A., Pehl, M., Pietzcker, R. C., Piontek, F., Rauner, S., Rodrigues, R., Rottoli, M., Schreyer, F., Schultes, A., Soergel, B., Soergel, D., Strefler, J., Ueckerdt, F., Kriegler, E. \& Luderer, G. REMIND2.1: transformation and innovation dynamics of the energy-economic system within climate and sustainability limits. Geoscientific Model Development 14, 6571-6603. www . doi .org/10.5194/gmd-14-6571-2021 (2021).

46. Pye, S., Butnar, I., Cronin, J., Welsby, D., Price, J., Dessens, O., Solano Rodríguez, B., Winning, M., Anandarajah, G., Scamman, D. \& Keppo, I. The TIAM-UCL Model (Version 4.1.1) Documentation Report (University College London, 2020). https:

//www.ucl.ac.uk/drupal/site_energymodels/sites/energy-

models/files/tiam-ucl-manual.pdf.

47. Capellán-Pérez, I., de Blas, I., Nieto, J., de Castro, C., Miguel, L. J., Carpintero, Ó., Mediavilla, M., Lobejón, L. F., Ferreras-Alonso, N., Rodrigo, P., Frechoso, F. \& Álvarez-Antelo, D. MEDEAS: a new modeling framework integrating global biophysical and socioeconomic constraints. Energy and Environmental Science 13, 986-1017. www.doi.org/10.1039/c9ee02627d (2020).

48. Sterman, J. D., Fiddaman, T., Franck, T., Jones, A., McCauley, S., Rice, P., Sawin, E. \& Siegel, L. Management flight simulators to support climate negotiations. Environmental Modelling and Software 44, 122-135. www . doi.org/10.1016/j.envsoft. 2012.06.004 (2013).

49. King, C. Interdependence of Growth, Structure, Size and Resource Consumption During an Economic Growth Cycle. arXiv Preprint. https://ideas.repec.org/p/ arx/papers/2106.02512.html (2021).

50. Victoria, M., Haegel, N., Peters, I. M., Sinton, R., Jäger-Waldau, A., del Cañizo, C., Breyer, C., Stocks, M., Blakers, A.,

Kaizuka, I., Komoto, K. \& Smets, A. Solar photovoltaics is ready to power a sustainable future. Joule 5, 1041-1056. www.doi.org/10. 1016/j.joule.2021.03.005 (2021).

51. International Energy Agency. Data and statistics - renewables and waste Web Page. 2020. https://www . iea.org/data-andstatistics/datatables? country=WORLD\&energy= Renewables $\% 20 \% 26 \% 20$ waste\&year $=2018$.

52. Bogdanov, D., Farfan, J., Sadovskaia, K., Aghahosseini, A., Child, M., Gulagi, A., Oyewo, A. S., de Souza Noel Simas Barbosa, L. \& Breyer, C. Radical transformation pathway towards sustainable electricity via evolutionary steps. Nat Commun 10, 1077. www .doi .org/10.1038/s41467-019-088551 (2019).

53. Zickfeld, K., MacDougall, A. H. \& Matthews, H. D. On the proportionality between global temperature change and cumulative CO 2 emissions during periods of net negative CO 2 emissions. Environmental Research Letters 11, 1-10.

www . doi.org/10.1088/17489326/11/5/055006 (2016).

54. Zickfeld, K., Azevedo, D., Mathesius, S. \& Matthews, H. D. Asymmetry in the climate-carbon cycle response to positive and negative CO2 emissions. Nature Climate Change 11, 613-617.

www . doi .org/10.1038/s41558-021-010612 (2021).

55. Fortmann-Roe, S. Insight Maker: A general-purpose tool for web-based modeling and simulation. Simulation Modelling Practice and Theory 47, 28-45. www.doi. org/10.1016/j.simpat.2014.03.013 (2014).

56. Görig, M. \& Breyer, C. Energy learning curves of PV systems. Environmental Progress and Sustainable Energy 35, 914-923. www.doi.org/10.1002/ep.12340 (2016). 
57. Fraunhofer Institut for Solar Energy Systems. Photovoltaics report Report (ISE, 2021). https://www.ise.fraunhofer.de/de/ veroeffentlichungen/studien/ photovoltaics-report.html.

58. Barlas, Y. Formal aspects of model validity and validation in system dynamics. System Dynamics Review 12, 183-210 (1996).

59. Crenna, E., Gauch, M., Widmer, R., Wäger, P. \& Hischier, R. Towards more flexibility and transparency in life cycle inventories for Lithium-ion batteries. Resources, Conservation and Recycling $\mathbf{1 7 0 .}$ www.doi.org/10.1016/j.resconrec. 2021. 105619 (2021).

60. Bauer, C., Bolliger, R., Tuchschmid, M. \& Faist-Emmenegger, M. in Sachbilanzen von Energiesystemen: Grundlagen für den ökologischen Vergleich von Energiesystemen und den Einbezug von Energiesystemen in Ökobilanzen für die Schweiz (ed Dones, R.) (Paul Scherer Institut, Swiss center for life cycle inventories, Dübendorf, Switzerland, 2007).

61. Zhang, X., Bauer, C., Mutel, C. L. \& Volkart, K. Life Cycle Assessment of Power-to-Gas: Approaches, system variations and their environmental implications. Applied Energy 190, 326-338. www.doi.org/ 10.1016/j . apenergy. 2016.12.098 (2017).

62. Bui, M., Adjiman, C. S., Bardow, A., Anthony, E. J., Boston, A., Brown, S., Fennell, P. S., Fuss, S., Galindo, A., Hackett, L. A., Hallett, J. P., Herzog, H. J., Jackson, G., Kemper, J., Krevor, S., Maitland, G. C., Matuszewski, M., Metcalfe, I. S., Petit, C., Puxty, G., Reimer, J., Reiner, D. M., Rubin, E. S., Scott, S. A., Shah, N., Smit, B., Trusler, J. P. M., Webley, P., Wilcox, J. \& Mac Dowell, N. Carbon capture and storage (CCS): the way forward. Energy and Environmental Science 11, 1062-1176. www.doi.org/10.1039/c7ee02342a (2018).

63. Sutter, D., Gazzani, M. \& Mazzotti, M. A low-energy chilled ammonia process exploiting controlled solid formation for post-combustion CO2 capture. Faraday Discuss 192, 59-83. www.doi.org/10.1039/c6fd00044d (2016).

64. Voldsund, M., Gardarsdottir, S., De Lena, E., Pérez-Calvo, J.-F., Jamali, A., Berstad, D., Fu, C., Romano, M., Roussanaly, S., Anantharaman, R., Hoppe, H., Sutter, D., Mazzotti, M., Gazzani, M., Cinti, G. \&
Jordal, K. Comparison of Technologies for CO2 Capture from Cement

Production-Part 1: Technical Evaluation. Energies 12.

www.doi.org/10.3390/en12030559 (2019).

65. Wang, Y., Zhao, L., Otto, A., Robinius, M. \& Stolten, D. A Review of Post-combustion CO2 Capture Technologies from Coal-fired Power Plants. Energy Procedia 114, 650-665. www.doi.org/10.1016/j.egypro.2017.03. 1209 (2017).

66. Gambhir, A. \& Tavoni, M. Direct Air Carbon Capture and Sequestration: How It Works and How It Could Contribute to Climate-Change Mitigation. One Earth 1, 405-409. www.doi.org/10.1016/j .oneear . 2019.11.006 (2019).

67. American Physial Society. Direct Air Capture of CO2 with Chemicals - A Technology Assessment for the APS Panel on Public Affairs Report (APS, 2011). https: //www . aps.org/policy/reports/popareports/loader. cfm?csModule=security/ getfile\&PageID=244407.

68. Breyer, C., Fasihi, M. \& Aghahosseini, A. Carbon dioxide direct air capture for effective climate change mitigation based on renewable electricity: a new type of energy system sector coupling. Mitigation and Adaptation Strategies for Global Change 25, 43-65. www . doi.org/10.1007/s11027-0199847-y (2019).

69. De Jonge, M. M. J., Daemen, J., Loriaux, J. M., Steinmann, Z. J. N. \& Huijbregts, M. A. J. Life cycle carbon efficiency of Direct Air Capture systems with strong hydroxide sorbents. International Journal of Greenhouse Gas Control $\mathbf{8 0}$, 25-31. www.doi.org/10.1016/j.ijggc. 2018.11.011 (2019).

70. Fasihi, M., Efimova, O. \& Breyer, C. Techno-economic assessment of $\mathrm{CO} 2$ direct air capture plants. Journal of Cleaner Production 224, 957-980. www.doi.org/10. 1016/j.jclepro.2019.03.086 (2019).

71. IPCC. IPCC Special Report on Carbon Dioxide Capture and Storage Report ISBN-13 978-0-521-86643-9 (Intergovernmental Panel on Climate Change, 2006).

72. Deutz, S. \& Bardow, A. Life-cycle assessment of an industrial direct air capture process based on temperature-vacuum swing adsorption. Nature Energy 6, 203-213. www . doi .org/10.1038/s41560-020-007719 (2021). 
73. Zerobin, F. \& Pröll, T. Concentrated Carbon Dioxide (CO2) from Diluted Sources through Continuous Temperature Swing Adsorption (TSA). Industrial and Engineering Chemistry Research 59, 9207-9214. www.doi.org/10.1021/acs.iecr.9b06177 (2020).

74. Zhang, X., Singh, B., He, X., Gundersen, T., Deng, L. \& Zhang, S. Post-combustion carbon capture technologies: Energetic analysis and life cycle assessment. International Journal of Greenhouse Gas Control 27, 289-298. www.doi.org/10. 1016/j.ijggc.2014.06.016 (2014).

75. Griscom, B. W., Adams, J., Ellis, P. W., Houghton, R. A., Lomax, G., Miteva, D. A., Schlesinger, W. H., Shoch, D., Siikamaki, J. V., Smith, P., Woodbury, P., Zganjar, C., Blackman, A., Campari, J., Conant, R. T., Delgado, C., Elias, P., Gopalakrishna, T., Hamsik, M. R., Herrero, M., Kiesecker, J., Landis, E., Laestadius, L., Leavitt, S. M., Minnemeyer, S., Polasky, S., Potapov, P., Putz, F. E., Sanderman, J., Silvius, M. Wollenberg, E. \& Fargione, J. Natural climate solutions. Proc Natl Acad Sci USA 114, 11645-11650.

www . doi .org/10.1073/pnas. 1710465114 (2017).

76. Creutzig, F., Breyer, C., Hilaire, J., Minx, J., Peters, G. P. \& Socolow, R. The mutual dependence of negative emission technologies and energy systems. Energy and Environmental Science 12, 1805-1817. www .doi.org/10.1039/c8ee03682a (2019).

77. Bogdanov, D., Ram, M., Aghahosseini, A., Gulagi, A., Oyewo, A. S., Child, M., Caldera, U., Sadovskaia, K., Farfan, J., De Souza Noel Simas Barbosa, L., Fasihi, M., Khalili, S., Traber, T. \& Breyer, C. Low-cost renewable electricity as the key driver of the global energy transition towards sustainability. Energy 227. www.doi .org/10. 1016/j . energy. 2021.120467 (2021).

78. Millward-Hopkins, J., Steinberger, J. K., Rao, N. D. \& Oswald, Y. Providing decent living with minimum energy: A global scenario. Global Environmental Change 65. www.doi.org/10.1016/j.gloenvcha. 2020 . 102168 (2020).

79. $2000 \mathrm{~W}$ Society. Worum geht es bei der 2000-Watt-Gesellschaft? Web Page. 2019. https://www.1ocal- energy.swiss/programme/2000-wattgesellschaft $\% 5 \mathrm{C \# /.}$

80. UN Department of Economic and Social Affairs. World Population Prospects 2019: Highlights Report ST/ESA/SER:A/423 (United Nations, 2019). https:// population.un.org/wpp/Publications/.

81. International Energy Agency. Energy Balance for the World Web Page. 2021. https://www.iea.org/Sankey/\%5C\#?c= World\&s=Balance.

82. Cullen, J. M. \& Allwood, J. M. Theoretical efficiency limits for energy conversion devices. Energy 35, 2059-2069. www.doi.org/10. 1016/j . energy . 2010.01.024 (2010).

83. Gruber, N., Clement, D., Carter, B. R., Feely, R. A., van Heuven, S., Hoppema, M., Ishii, M., Key, R. M., Kozyr, A., Lauvset, S. K., Lo Monaco, C., Mathis, J. T., Murata, A., Olsen, A., Perez, F. F., Sabine, C. L., Tanhua, T. \& Wanninkhof, R. The oceanic sink for anthropogenic CO2 from 1994 to 2007. Science 363, 1193-1199. www.doi.org/10.1126/science.aau5153 (2019).

84. IPCC. Climate Change 200\%: The Physical Science Basis. Contribution of Working Group I to the Fourth Assessment Report of the Intergovernmental Panel on Climate Change Report ISBN 9780521 88009-1 (Intergovernmental Panel on Climate Change, 2007).

85. Stein, R. Accumulation of Organic Carbon in Marine Sediments (Springer, 1991).

86. Desing, H., Braun, G. \& Hischier, R. Ecological resource availability: a method to estimate resource budgets for a sustainable economy. Global Sustainability 3, 1-11. www.doi.org/10.1017/sus. 2020.26 (2020).

87. Hansen, J., Sato, M., Kharecha, P., Beerling, D. J., Berner, R. Masson-Delmotte, V., Pagani, M., Raymo, M., Royer, D. L. \& Zachos, J. C. Target Atmospheric CO2: Where Should Humanity Aim? The Open Atmospheric Science Journal 2, 217-231 (2008).

88. Barnhart, C. J. \& Benson, S. M. On the importance of reducing the energetic and material demands of electrical energy storage. Energy and Environmental Science 6. www. doi .org/10.1039/c3ee24040a (2013). 
89. Barnhart, C. J., Dale, M., Brandt, A. R. \& Benson, S. M. The energetic implications of curtailing versus storing solar- and wind-generated electricity. Energy and Environmental Science 6. www.doi.org/10.1039/c3ee41973h (2013).

90. Al-Habaibeh, A. Should we turn the Sahara Desert into a huge solar farm? Blog. 2019. https://theconversation. com/shouldwe-turn-the-sahara-desert-into-ahuge-solar-farm-114450.

91. Ryser, S. The Anti-Politics Machine of Green Energy Development: The Moroccan Solar Project in Ouarzazate and Its Impact on Gendered Local Communities. Land 8. www. doi.org/10.3390/land8060100 (2019).

92. Lu, Z., Zhang, Q., Miller, P. A., Zhang, Q., Berntell, E. \& Smith, B. Impacts of Large-Scale Sahara Solar Farms on Global Climate and Vegetation Cover. Geophysical Research Letters 48.

www.doi.org/10.1029/2020g1090789 (2021).
93. Rao, N. D. \& Min, J. Decent Living Standards: Material Prerequisites for Human Wellbeing. Soc Indic Res 138, 225-244.

https://www.ncbi.nlm.nih.gov/pubmed/ 29950752 (2018).

94. Kikstra, J. S., Mastrucci, A., Min, J., Riahi, K. \& Rao, N. D. Decent living gaps and energy needs around the world. Environmental Research Letters 16. www.doi.org/10.1088/1748-9326/ac1c27 (2021).

95. Welsby, D., Price, J., Pye, S. \& Ekins, P. Unextractable fossil fuels in a 1.5 degrees $\mathrm{C}$ world. Nature 597, 230-234.

www . doi .org/10.1038/s41586-021-038218 (2021).

96. Zhang, Y., Kim, M., Wang, L., Verlinden, P. \& Hallam, B. Design considerations for multi-terawatt scale manufacturing of existing and future photovoltaic technologies: challenges and opportunities related to silver, indium and bismuth consumption. Energy and Environmental Science 14, 5587-5610. www.doi.org/10.1039/d1ee01814k (2021). 


\section{Supplementary materials to "The 3-machines energy transition model: exploring the energy frontiers for restoring a habitable climate"}

Harald Desing*1, Andreas Gerber ${ }^{1}$, Roland Hischier ${ }^{1}$, Patrick Wäger ${ }^{1}$, and Rolf Widmer ${ }^{1}$

1 Empa - Swiss Federal Laboratories for Material Science and Technology, Lerchenfeldstrasse

5, 9014 St. Gallen, Switzerland

* corresponding author: harald.desing@empa.ch

This section provides details of the modelling rationale, the implemented structure in InsigthMaker [55] as well as additional figures. The entire model implemented in InsightMaker is available online under https://insightmaker.com/insight/2swt92w2TnkTv37vM97BZX/3-machines-release1.

\section{S1 Energy system}

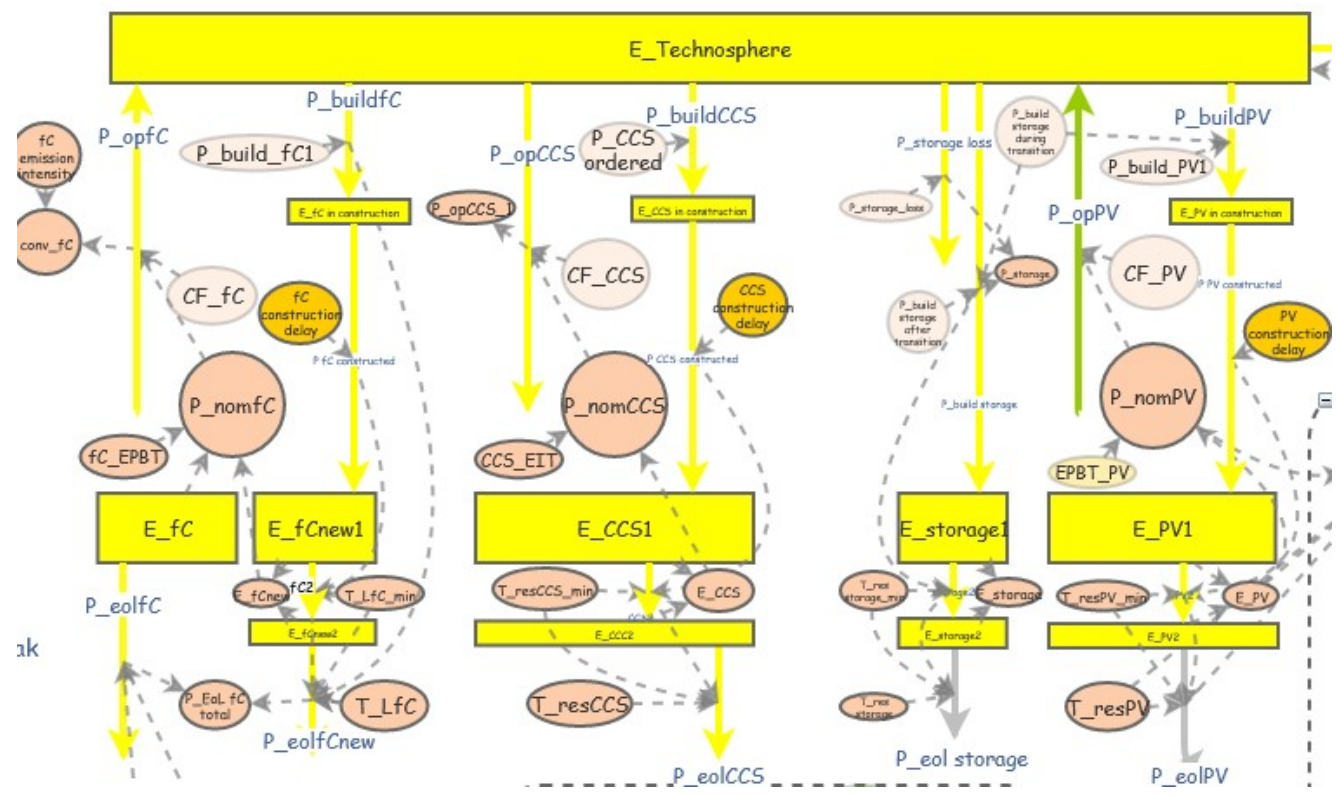

Figure S1: Energy system module structure

Each of the three machines in the energy system consists of a stock of energy, i. e. embodied energy. This embodied energy is increased by power $P_{\text {build, } \mathrm{X}}$ to grow the engine and decreased by an end-of-life process. End-of-life is modelled as a two step outflow of power from the embodied energy stock: First, the embodied energy is transferred to a sub-compartment of the embodied energy $\left(E_{\mathrm{X}, 2}\right)$ after a fixed time span (i. e. after the minimum lifetime $t_{\mathrm{L}, \mathrm{X}, \mathrm{min}}$ ). From this sub-compartment, the end-of-life outflow is a third order delay function from the inflow into this sub-compartment, determined by the time difference between the average $t_{\mathrm{L}, \mathrm{X}, \text { avg }}$ and minimum lifetime. In this way, the engine does not die out immediately, but over a extended period of time. In other words, not every building block of the engine has the same lifetime. The construction of the machine is delayed by a first order delay by the construction delay time 
( $\left.\Delta t_{\text {construction delay }}\right)$, representing the construction time from commissioning to start of operation. This delay is smoothing also abrupt changes in the system.

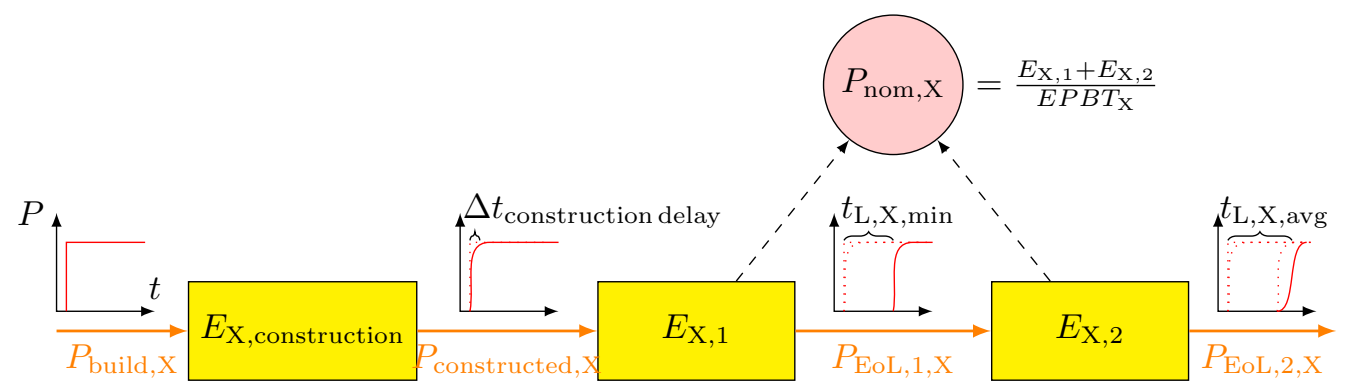

Figure S2: Machine structure: relation between embodied energy and nominal (installed) capacity as well as end-of-life modelling of a machine $X$.

The installed capacity of each engine is proportional to the embodied energy with the energy payback time (EPBT):

$$
P_{\text {nom }, \mathrm{X}}=\frac{E_{\mathrm{X}}}{E P B T_{\mathrm{X}}}
$$

The capacity factor $(\mathrm{CF})$ of each engine determines the fraction of nominal power that is delivered to the grid:

$$
P_{\mathrm{op}, \mathrm{X}}=L F \cdot P_{\mathrm{nom}, \mathrm{X}}
$$

CF can be adjusted by the system controller to ensure that the energy system meets the demand from society.

The energy grid $\left(E_{\text {Techs }}\right)$ is modelled as a stock which collects and distributes power. The value of the stock is in the model proportional to the supply to society, however, it has no physical function or interpretation in reality. Removing this stock from the model is possible and does not change any of the results. However, representing the grid as a stock is more intuitive and, as it doesn't have an influence on the results, it remains part of the model.

\section{S1.1 Fossil engine}

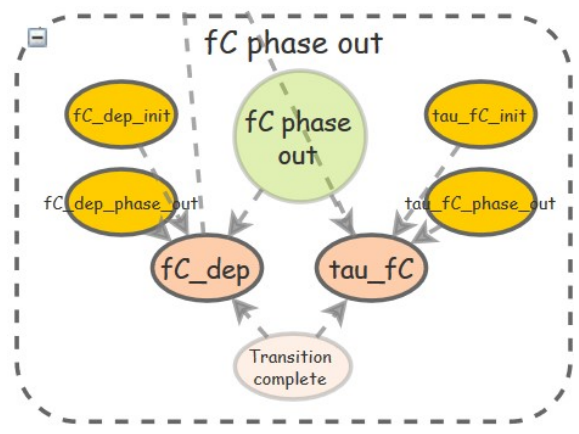

Figure S3: Fossil engine phase out module structure

The energy payback time (EPBT) for fossil power plants is about $E P B T_{\mathrm{fC}}=3 \mathrm{a}\left(\mathrm{see}^{4}\right)$. With this, the embodied energy of the fossil engine is initialized to $E_{\mathrm{fC}}(t=0)=25.2 \mathrm{TWa}$. This initial stock of the fossil engine is modelled to die out according to an exponential decay, as the age of each individual power plant is not modelled. Any newly build fossil capacity is added to a "new" stock and its end-of-life modelled according to the general model (see Fig. S2).

New fossil capacity is build for two reasons:

\footnotetext{
${ }^{4}$ https://publications.parliament.uk/pa/ld200304/ldselect/ldsctech/126/12620.htm
} 
1. replacement of end-of-life capacity (repair): only happens when the repair switch $f C$ repair is turned on, the transition is not completed and the load factor of the fossil engine $C F_{\mathrm{fC}}>0$ (i. e. the fossil engine is still in operation). Repair of the fossil engine (if switched on) can only be equal to EoL.

2. growth: the fossil engine can be grown to meet a growing demand in society (delta for growing with demand) or explicitly (e.g. for building and operating the carbon scrubber, delta in transition).

No fossil fuel shifts (e.g. coal/oil $\rightarrow$ gas) are considered in the model. The simulation starts with the fossil engine delivering the required $6.3 \mathrm{TW}$ of annual final power to society (Section S2). The installed capacity is $P_{\text {nom, } \mathrm{fC}}=8.4 \mathrm{TW}$, considering that the capacity factor of current power plants as $C F_{\mathrm{el}}=0.5$ [97] and electricity constitutes around $40 \%$ of total final energy [31, 81]. As the fossil engine comprises also mobility and heat sectors in the model, the initial $\mathrm{CF}$ starts with $C F_{\mathrm{fC}}=0.75$.

\section{S1.2 Solar engine}

Direct solar energy conversion is commonly underestimated in IAMs [41], despite having the largest potential within Earth system boundaries and considering the chemical energy demand of society [37]. Additionally, most other renewable energy resources (e.g. wind, hydro or biomass) are close to or already beyond their environmentally safe limits and can therefore not significantly contribute to replacing the fossil engine [31, 98]. In this model, the solar engine is thus entirely based on photovoltaic (PV) technology. The installed capacity is limited to $A T P_{\mathrm{PV}}$,built environment $=21 \mathrm{TW}$, which is the safe limit on already sealed surfaces of the built environment, or up to $A T P_{\mathrm{PV}}=70 \mathrm{TW}$ when including parts of the world's deserts (confidence: $99 \%$ ) [37]. The parameter desert potential fraction defines the fraction of the desert potential, which may be developed.

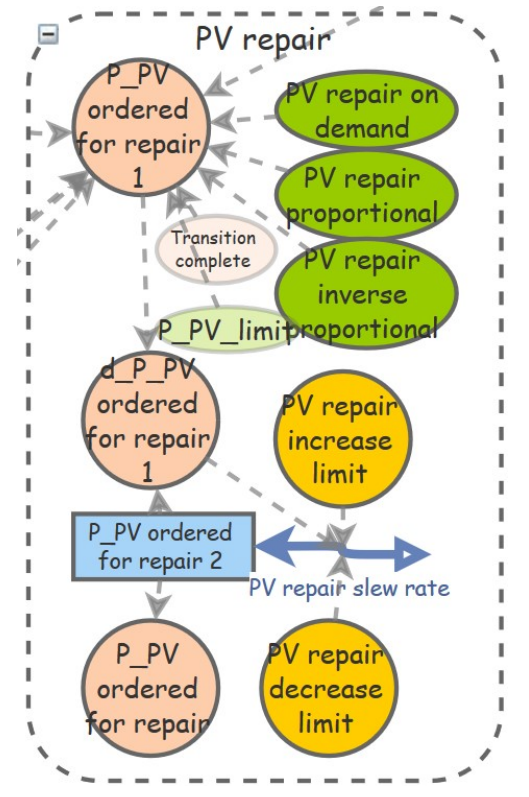

Figure S4: PV repair module structure

A rapid initial growth of the solar engine causes very high power demand during the first and second replacement cycles, which may be difficult/impossible to provide once the fossil engine is shut down. The model allows for the following repair/replace options: First, the solar engine is repaired on demand, similar to the fossil engine, i. e. end-of-life capacity is replaced instantaneously. A second strategy is to build replacement ahead of time, i. e. after the transition is completed and before the initial installation reaches end-of-life. This preventative maintenance can be adjusted proportionally to the installed capacity and inversely proportional to the oversize of the solar engine relative to required demand.

$$
P_{\text {repair }, \mathrm{PV}}=\zeta_{\mathrm{PV}, \text { repair,inv.prop }} \frac{1(\mathrm{TW})^{2}}{P_{\mathrm{nom}, \mathrm{PV}}-P_{\text {demand,req }}}+\zeta_{\mathrm{PV}, \text { repair,prop }} \frac{E_{\mathrm{PV}}}{T_{\mathrm{PV}, \text { res }}}
$$


EPBT for solar energy is set by technological parameters of PV systems and taken here as $E P B T_{\mathrm{PV}}=$ 1.5 a $[31,57,99-102]$. Technological improvements reducing embodied energy demand $[56,57]$ are not considered here, as in fast transitions the energy learning may not materialize [32].

\section{S1.2.1 Storage as part of solar engine}

Direct solar energy conversion is inherently variable, following cyclical daily and seasonal patterns. Additionally, weather events (e.g. extended periods of cloud coverage) make the variability less predictable. There are two basic ways to manage non-matching supply:

- demand management: electricity is consumed when the sun shines [32]. This strategy may appear inconvenient but is the most effective environmentally, as it does not require any additional infrastructure. For certain energy uses, this strategy is possible (e.g. washing machine); for others not (e.g. lighting). Depending on the extent society is willing to shift its demand to sunshine hours, storage options are necessary.

- storage (mechanical, electro-chemical, chemical or thermal [103]): requires to build infrastructure (e. g. hydro reservoirs, batteries, synfuel plants) and inflicts energy losses (limited round-trip efficiency for charging-discharging cycles).

Storage independence time ranges from zero (i. e. no storage, perfect alignment of energy demand with solar supply) to several months, fully balancing seasonal variations (i. e. constant supply at any moment throughout the year) [32].

Different storage technologies can be combined by giving relative weights to the three storage types in the model: mechanical, chemical and electro-chemical (see Section S1.2.3).

Storage has to provide the fraction $\phi$ of demand throughout a chosen independence time $\Delta t_{i}$ [32]. Storage capacity $E_{\text {storage capacity }}$ therefore needs to be:

$$
E_{\text {storage capacity }}=\Delta t_{i} \cdot \phi \frac{P_{\text {demand,stored }}}{\eta_{\text {out }}}
$$

This required storage capacity is built during the transition alongside with the solar engine. During the transition, the storage size is proportional to solar capacity. Once it reaches the required size to fulfill $\phi$ for demand by society, it remains proportional to demand only.

Compensation for storage losses is the second power demand of storage. It depends on the round-trip efficiency $\eta$ and the fraction of demand $\phi$, which is actually stored. This fraction has two components: first, daily storage, which is a function of how well the annual average of daily demand follows solar supply [32]; second, seasonal storage, which is modelled proportional to independence time $\Delta t_{i}>0.0016 \mathrm{a}$.

\section{S1.2.2 Energy storage relationships}

Energy storage options are modelled as a combination of three exemplary storage technologies (i. e. Li-ion batteries [59], pumped hydro storage [60] and synthetic $\mathrm{CH}_{4}$ [61]). The relevant parameters energy intensity of storage capacity $E I_{\text {storage }}$ and round-trip efficiency $\eta$ are defined and related as follows [32]. Energy intensity of storage capacity (dimensionless):

$$
\begin{array}{rll}
E I_{\text {storage }} & = & \frac{E_{\text {embodied }}}{E_{\text {storage capacity }}} \\
E_{\text {embodied }} & \cdots & \text { embodied energy in electric energy equivalents } \\
E_{\text {storage capacity }} & \cdots & \text { nominal storage capacity in regard to stored output energy }
\end{array}
$$

Round-trip efficiency $\eta$ (excluding embodied energy input per output, as this is already accounted for in $\left.E I_{\text {storage }}\right)$ :

$$
\begin{array}{rll}
\eta & =\frac{E_{\mathrm{el}, \mathrm{out}}}{E_{\mathrm{el}, \text { in }}}=\frac{E_{\mathrm{el}, \mathrm{out}}}{E_{\mathrm{el}, \mathrm{stored}}} \frac{E_{\mathrm{el}, \mathrm{stored}}}{E_{\mathrm{el}, \text { in }}}=\eta_{\mathrm{out}} \cdot \eta_{\mathrm{in}} \\
E_{\mathrm{el}, \text { out }} & \ldots & \text { electric energy output (for an average charge cycle or over whole lifetime) } \\
E_{\mathrm{el}, \text { in }} & \ldots & \text { electric energy input necessary to provide the output } \\
E_{\mathrm{el}, \text { stored }} & \ldots & \text { electric energy stored in storage technology }
\end{array}
$$




\section{S1.2.3 Mixing energy storage technologies}

Three exemplary energy storage options are modelled explicitly: mechanical, chemical and electro-chemical. The parameters energy intensity EI, round-trip efficiency $\eta$ and output efficiency $\eta_{\text {out }}$ can be chosen to reflect specific technologies or sets of technologies in the respective categories. The three storage technologies are mixed together according to the relative weight $\zeta$ specified by the user. If the sum of these weights is zero, each technology is weighted equally, i. e. 1/3. In all other cases, the fraction for each technology is set by the relative weight divided by the sum of all relative weights.

The combination of the three storage technologies leads to weighted parameters $\eta$ and $E I$ as follows:

$$
\begin{aligned}
\eta & =\frac{1}{\frac{\zeta_{\mathrm{M}}}{\eta_{\mathrm{M}}}+\frac{\zeta_{\mathrm{C}}}{\eta_{\mathrm{C}}}+\frac{\zeta_{\mathrm{E}}}{\eta_{\mathrm{E}}}} \\
\eta_{\text {out }} & =\frac{1}{\frac{\zeta_{\mathrm{M}}}{\eta_{\mathrm{out}, \mathrm{M}}}+\frac{\zeta_{\mathrm{C}}}{\eta_{\mathrm{out}, \mathrm{C}}}+\frac{\zeta_{\mathrm{E}}}{\eta_{\mathrm{out}, \mathrm{E}}}} \\
E I & =\eta_{\mathrm{out}}\left(E I_{\mathrm{M}} \frac{\zeta_{\mathrm{M}}}{\eta_{\mathrm{out}, \mathrm{M}}}+E I_{\mathrm{C}} \frac{\zeta_{\mathrm{C}}}{\eta_{\mathrm{out}, \mathrm{C}}}+E I_{\mathrm{E}} \frac{\zeta_{\mathrm{E}}}{\eta_{\mathrm{out}, \mathrm{E}}}\right)
\end{aligned}
$$

\section{S1.3 Carbon scrubber}

Carbon capture and storage (CCS), here understood as any technology capturing $\mathrm{CO}_{2}$ either from stack (post-combustion) or from the atmosphere [62], is necessary to reduce atmospheric $\mathrm{CO}_{2}$ concentration to $350 \mathrm{ppm}$ within this century. However, this comes at substantial energy costs.

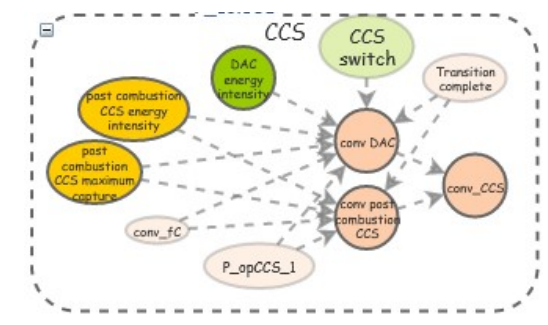

Figure S5: CCS module structure

CCS can either be post-combustion using fossil power plants' exhaust [63-65]; or direct air capture (DAC) [66-71] removing directly from the air. The main difference in the two methods is the energy requirement for capturing $\mathrm{CO}_{2}$. For post combustion capture from flue gas, $\mathrm{CO}_{2}$ is at a much higher concentration than in the atmosphere, which reduces the energy demand. Post-combustion capture has a capture efficiency of about $90 \%[63-65,74]$ and we estimate that it can be implemented for a maximum of $50 \%$ of all fossil emissions, as many point-sources are decentralized (e.g. domestic heating systems) or mobile (e.g. cars, aircrafts). As long as fossil power plants are operated, the carbon scrubber removes concentrated $\mathrm{CO}_{2}$ from their stacks. The energy intensity of post-combustion capture is approximately $E I_{\mathrm{CCS}}=0.06 \mathrm{TWa} / \mathrm{Gt}[73,74]$. Any emissions in excess of the fraction capturable at stack need to be removed from the atmosphere.

The energy intensity of DAC is generally lower for low temperature DAC (operating at $\approx 100^{\circ} \mathrm{C}$ ) with about $E I_{\mathrm{ltDAC}}=[0.06,0.15] \mathrm{TWa} / \mathrm{Gt}[70,73,76,104]$; than for high temperature DAC (operating at $\left.\approx 900^{\circ} \mathrm{C}\right)$ with about $E I_{\mathrm{htDAC}}=[0.17,0.31] \mathrm{TWa} / \mathrm{Gt}[69,70,104]$. Thermal energy is thereby converted to electric energy equivalents through a heat pump with $C O P_{\text {ltDAC }}=3$ for ltDAC and direct conversion (i. e. $C O P_{\mathrm{htDAC}}=1$ ) for htDAC. For our simulation experiments we use a value of $E I_{\mathrm{DAC}}=0.2 \mathrm{TWa} / \mathrm{Gt}$.

The carbon scrubber differs from the other two machines in that it does not feed power into the grid. It draws power for both its growth (embodied energy) and its operation (i. e. removal of $\mathrm{CO}_{2}$ from the atmosphere). It does not have an energy payback time EPBT, but an energy investment time (EIT) instead, which is the time the CCS machine has to be operated at full capacity until the operational energy over this time interval equals the embodied energy. We estimate EIT using the inventory of a high temperature DAC facility [69] and the operational power demand for a wide range of low and high temperature DAC systems $[69,70,73,76,104]$. For simplicity, we do not consider the differences in plant design of high or low temperature DAC or post-combustion CCS, assuming they would be similar in terms 
of material demand. This yields $E I T=[0.05,0.25]$ a, of which we use, in precaution and equally for DAC and post-combustion CCS, the upper limit for our simulation experiments.

Any idle capacity in the energy system can be used to grow and operate the carbon scrubber. It is designed to grow as long as there is idle capacity available. If CCS is operated through power from the fossil engine, it can be run up to its maximum capacity. When operated through the solar engine, it can only be operated to $32 \%$ of its nominal capacity. This is because it is then operated through solar power directly, not requiring storage (Section S1.3.1).

\section{S1.3.1 CCS vs. energy storage}

In this model, CCS is operated with the solar engine without storage. Therefore, the maximum average capacity factor is limited to $C F_{\mathrm{CCS}, \max }=0.318$, i. e. $32 \%$ of the nominal installed power can be operated average over the day. Alternatively, there is also the possibility to operate CCS at full capacity and provide solar power through storage. This requires to build and operate additional storage.

Removing $\mathrm{CO}_{2}$ from the atmosphere uses $E I_{\mathrm{DAC}}=0.2 \mathrm{~W} / \frac{\mathrm{kg}}{\mathrm{a}}$ of operational power $P_{\mathrm{CCS}}$,operational. To build the necessary infrastructure, additional power $P_{\mathrm{CCS} \text {,embodied }}$ is necessary:

$$
\begin{array}{rll}
P_{\mathrm{CCS}, \text { embodied }} & =\frac{P_{\mathrm{CCS}, \text { operational }}}{C F_{\mathrm{CCS}}} \frac{E I T_{\mathrm{CCS}}}{t_{\mathrm{L}, \mathrm{CCS}}} \\
E I T_{\mathrm{CCS}} & \ldots & \text { Energy investment time for CCS } \\
t_{\mathrm{L}, \mathrm{CCS}} & \ldots & \text { Lifetime of CCS infrastructure }
\end{array}
$$

If operational power is provided through storage, storage losses and embodied energy for required storage capacity have to be provided in addition by the solar engine [32].

$$
\begin{aligned}
P_{\text {solar supply to CCS }} & =P_{\mathrm{CCS}, \text { operational }}\left(1+\phi_{\mathrm{CCS}}\left(\frac{1}{\eta}-1\right)\right) \\
P_{\text {storage, CCS }, \text { embodied }} & =P_{\mathrm{CCS}, \text { operational }} \frac{\phi_{\mathrm{CCS}}}{\eta_{\text {out }}} \cdot \frac{\Delta t_{i}}{t_{\mathrm{L}, \text { storage }}} \cdot E I_{\text {storage }} \\
P_{\mathrm{CCS}, \text { total }} & =P_{\text {solar supply to CCS }}+P_{\text {storage }, \mathrm{CCS}, \text { embodied }}+P_{\mathrm{CCS}, \text { embodied }}
\end{aligned}
$$

In Tab. S1, a comparison between the total power required for CCS per unit of mass flow for four scenarios is provided using the formulae introduced in this section and data from the 3-machines model. The first scenario is without storage, as it is implemented in the model. The latter three scenarios include storage in such a way, that CCS can be operated at full nominal power (i. e. $C F_{\mathrm{CCS}}=1$ ). For these scenarios, the fraction of operational power for CCS needed to be stored is $\phi_{\mathrm{CCS}}=0.6$ and independence time $\Delta t_{i}=14.5 \mathrm{~h}=0.0016$ a [32]. As can be seen in Tab. S1, the scenario without storage has the lowest power requirement per mass flow of removed $\mathrm{CO}_{2}$.

It is, thus, energetically more expensive to provide power through storage to operate CCS continuously than operate it intermittently when solar supply is available, avoiding storage altogether. This justifies the implementation in the 3-machines model.

\section{S2 Demand}

Humanity's demand for annual average power is the required output of the energy system. In 2018 global final power demand in electric energy equivalents was $7.1 \mathrm{TW}$ (932 W/person, with renewable energy (RE) contributing $1.04 \mathrm{TW}[31,81,82]$. The current renewable energy system does not have to be replaced and is assumed constant thereafter. Furthermore, it consists of mainly RE other than PV, which are globally at or above their sustainable potentials [37]. Therefore, the current RE system is excluded in this model and does not contribute to the transition nor $\mathrm{CO}_{2}$ clean-up. Leaving the demand per person constant until the start of the transition beginning of 2022, leads to a initial demand from the still non-renewable energy system ${ }^{5}$ of $P_{\text {demand, } 0}=6.3 \mathrm{TW}$. Starting from there, power demand from society can either follow a specified trajectory or transition towards a target for power demand per person.

Different trajectories for power demand can be defined (Fig. S7). Exponential propagation is set as a default; which can model continued growth (growth rate $=0.03$ ), constant demand (growth rate $=0$ ) or

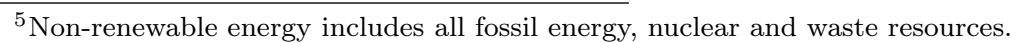




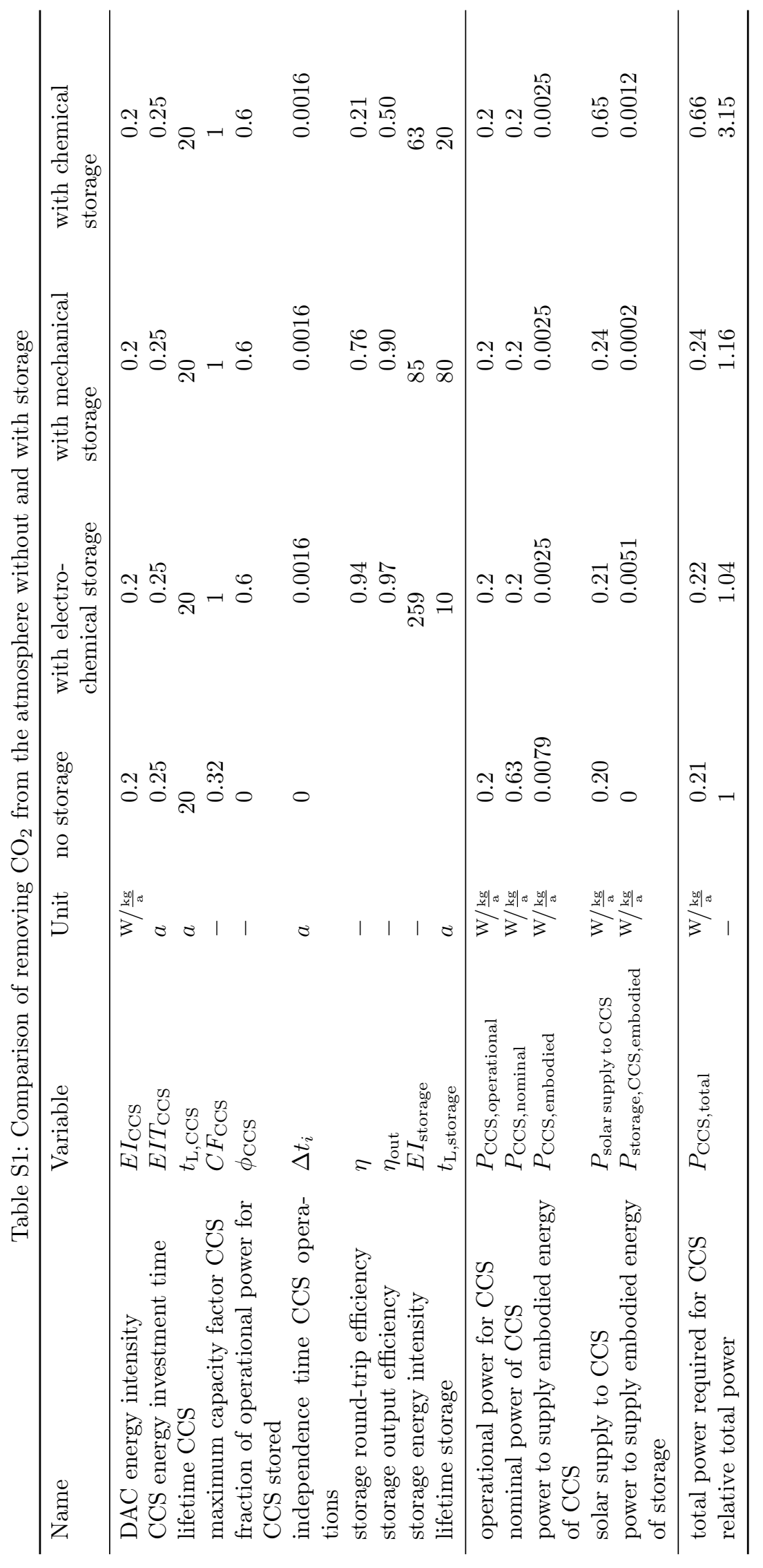




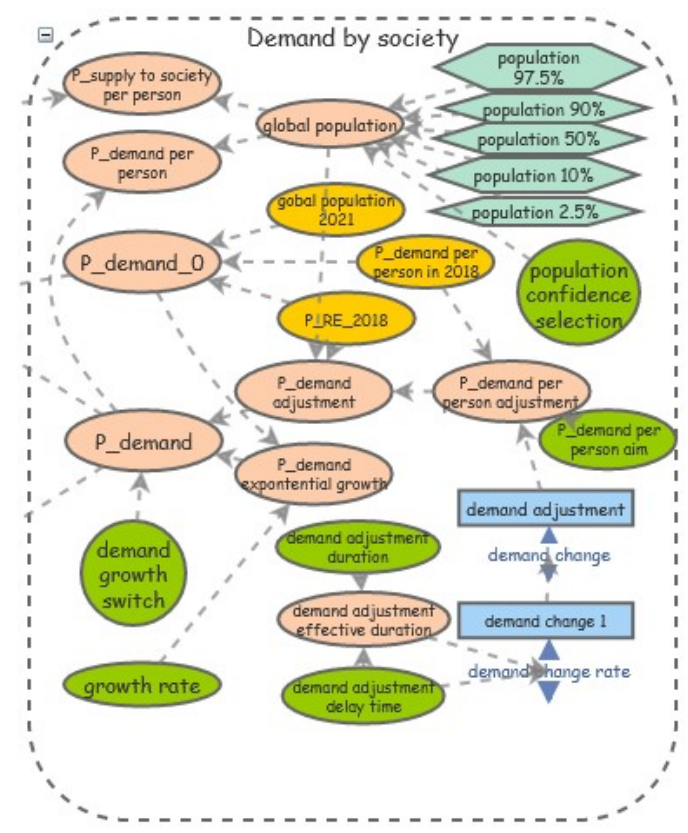

Figure S6: Demand module structure

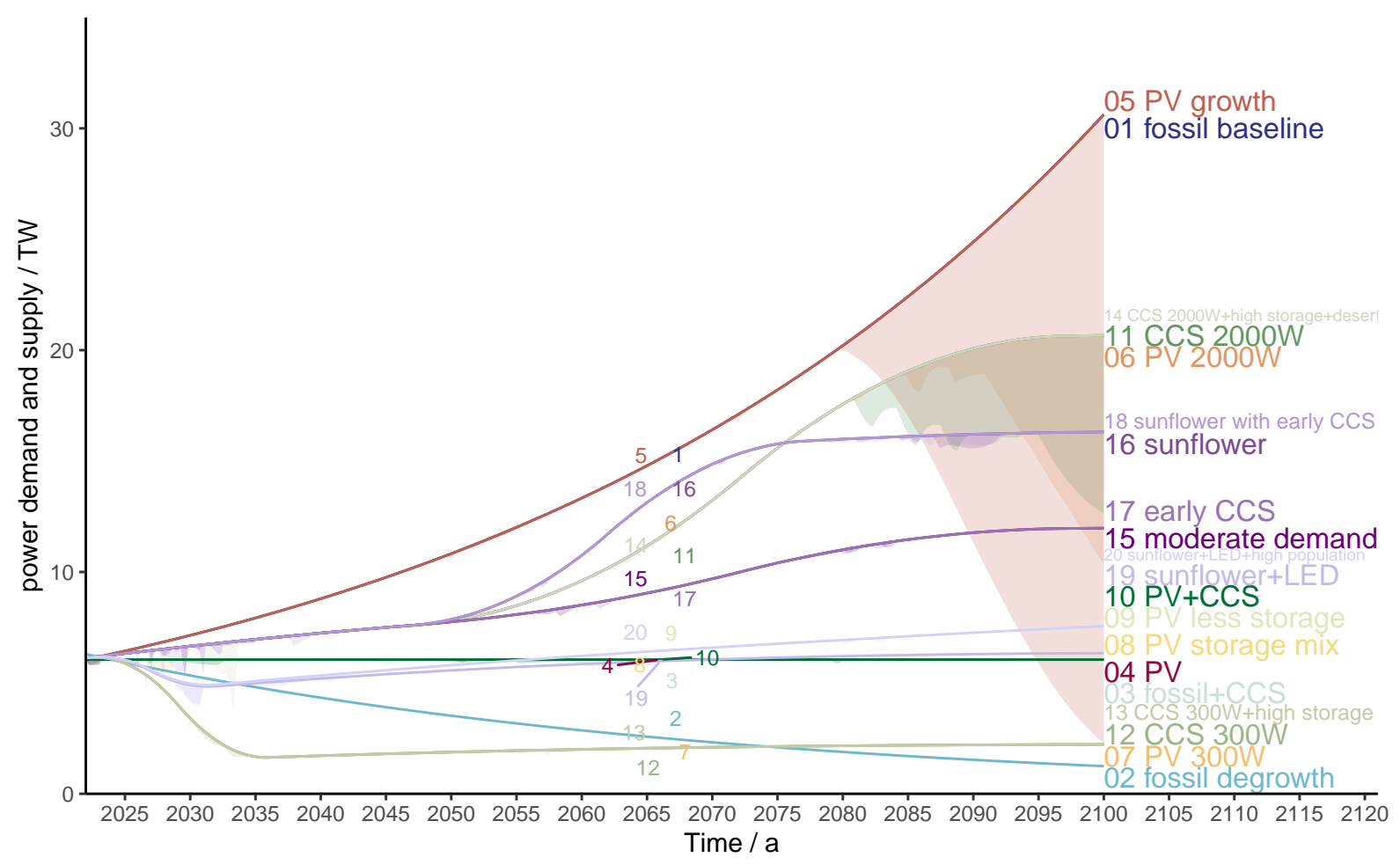

Figure S7: Power demand for all scenarios. 
degrowth (growth rate $<0$ ). The second option is the adjustment from current demand per person of $932 \mathrm{~W} / \mathrm{p}$ to a specified target within a defined time period.

World population is modelled according to UN population prospects 2019 [80]. The model allows to choose between five different levels of confidence for the estimate $P_{\mathrm{pop}}=\{0.025,0.1,0.5,0.9,0.975\}$, which means that a fraction of $P_{\text {pop }}$ of all population estimates lie below the specific projection. Population prospects influence the power demand for society.

\section{S3 System controller}

\section{S3.1 PID controller}

A proportional-integral-differential (PID) controller is used to ensure that supply meets society's demand. It adjusts power output of the fossil and solar engines by modulating their capacity factors (CF). The fossil engine's capacity factor is modulated and the CF of the solar engine is kept at one (i. e. no curtailment) during the transition. When the transition is completed, the solar engine takes over the entire supply and is adjusted to match supply and demand.

The difference in $\mathrm{CF}(\triangle C F)$ for both $\mathrm{PV}$ and $\mathrm{fC}$ is integrated to determine the respective $\mathrm{CF}$. As $\mathrm{CF}$ has to be in the interval between $C F=[0,1]$, the integration is caped by an outflow compensating excess inflows.

For certain parameter settings, the parameters of the PID controller need to be tuned to stabilize the supply to society. Making the model more user friendly, a more advanced control strategy may be implemented in the future.

\section{S3.2 Additional demand control}

Idle capacity in the system can be used to power additional demand for growing and operating the three machines. Idle capacity is thereby distributed hierarchically (Fig. S9).

During the transition, the first priority for additional demand is on growing the fossil engine if necessary. This is needed to maintain the fossil engine large enough to provide society's demand at all times during the transition. The fossil engine can be grown using a fixed fraction of idle capacity $(\delta \in[0,1])$ or in case the fossil engine's nominal capacity is smaller than oversize factor times demand, it can use a fraction proportional to the deviation ( $\left.\delta_{\text {for growing with demand }}\right)$.

The second priority is on growing the solar engine. The parameter $\beta \in[0,1]$ defines the share of the remaining free capacity (after the growth demand of the fossil engine is subtracted) invested in the growth of the solar engine. Additionally, the solar engine can grow directly proportional to its size by investing a fraction of its harvested energy $(\alpha \in[0,1])$ into its own growth (i. e. leading to exponential growth) [31].

The last priority is given to the carbon scrubber. A fraction $\epsilon \in[0,1]$ of the remaining idle capacity can be used to grow and operate the carbon scrubber. Power is automatically distributed to growth and operation so that the full allocated power is utilized. I.e. all power goes into operation if the available power is smaller than the usable installed capacity (i. e. limited by maximum capacity factor). Otherwise the carbon scrubber is grown with the available power in excess of operational power. The maximum capacity factor is a function of the contribution of solar energy to total supply. When CCS is operated with fossil power, it can be operated continuously (i. e. $C F_{-} C C S$, max, effective $=1$ ). When CCS is operated solely on solar power, it can only be operated during sunshine hours to avoid storage. Then the maximum average capacity factor for CCS is reduced to 0.4. The operation (and further growth) of the carbon scrubber is stopped if atmospheric $\mathrm{CO}_{2}$ concentration is below $350 \mathrm{ppm}$.

Both parameters $\beta$ and $\epsilon$ can be specified separately for the periods "in transition" and "transition completed".

\section{S3.3 Slew rate limiter}

In the model the rate of ramping up or down the growth of a machine (i.e. the available power) is limited. This reflects real world limitations, as resources e. g. natural, human and financial capital or production capacity, to build new machine capacity can only grow gradually. This behaviour is modelled with a slew rate limiter. It prevents flows from sudden changes (i. e. infinite derivatives), which may cause instabilities in dynamic systems. The used slew rate limiters are built according to (Fig. S10): First, the difference between the input variable and the limited variable is determined and divided by the simulation time step 


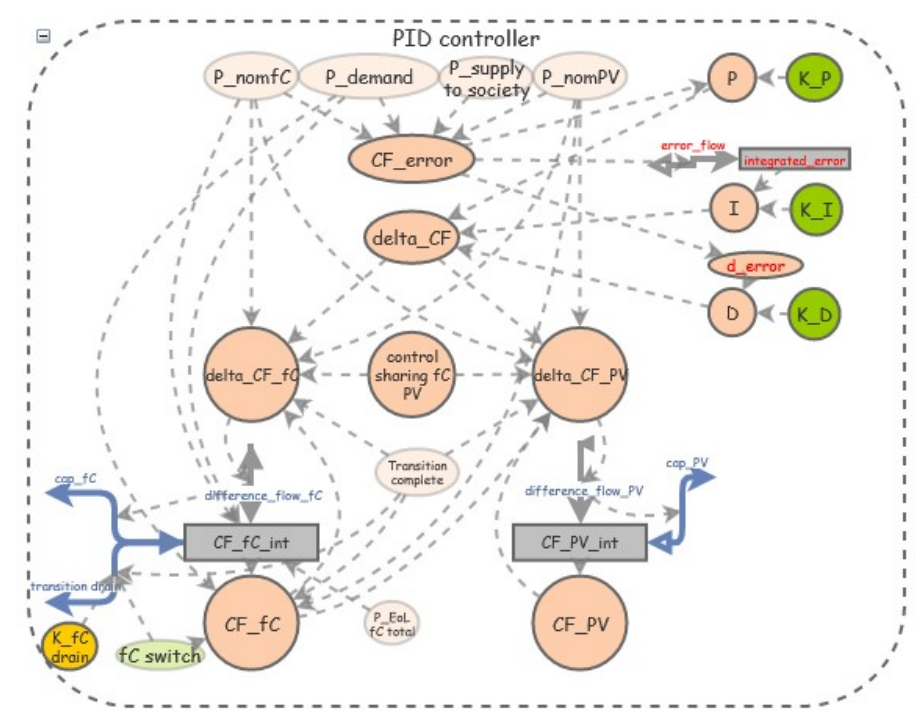

Figure S8: PID controller module structure

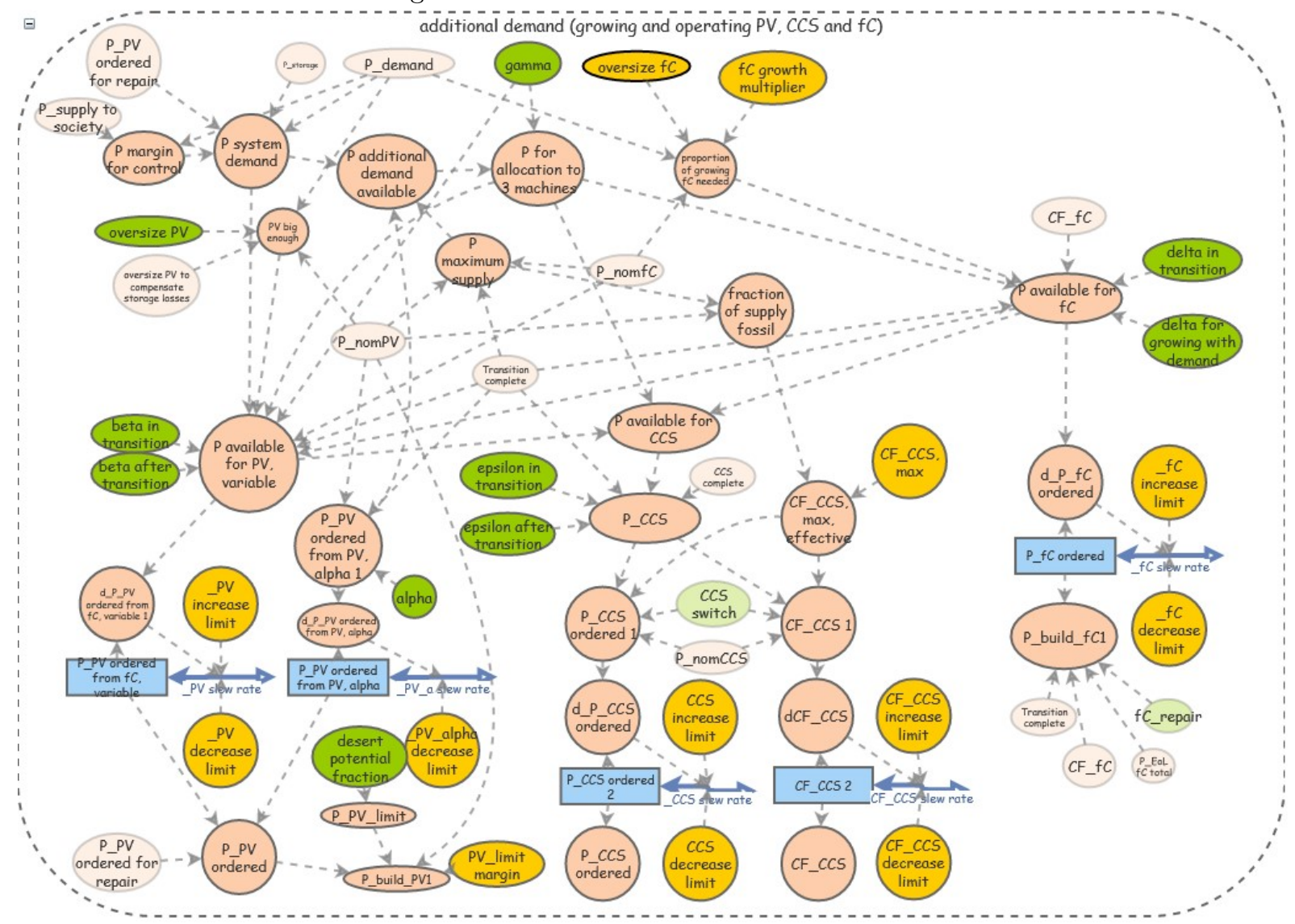

Figure S9: Controller module structure 
(i. e. a rate of change). This rate of change is limited by the increase and decrease limits. The limited rate is then integrated to provide the gradient limited variable. For example, a step input function is converted to a ramp-function, i. e. its slopes are limited to the slew rate.

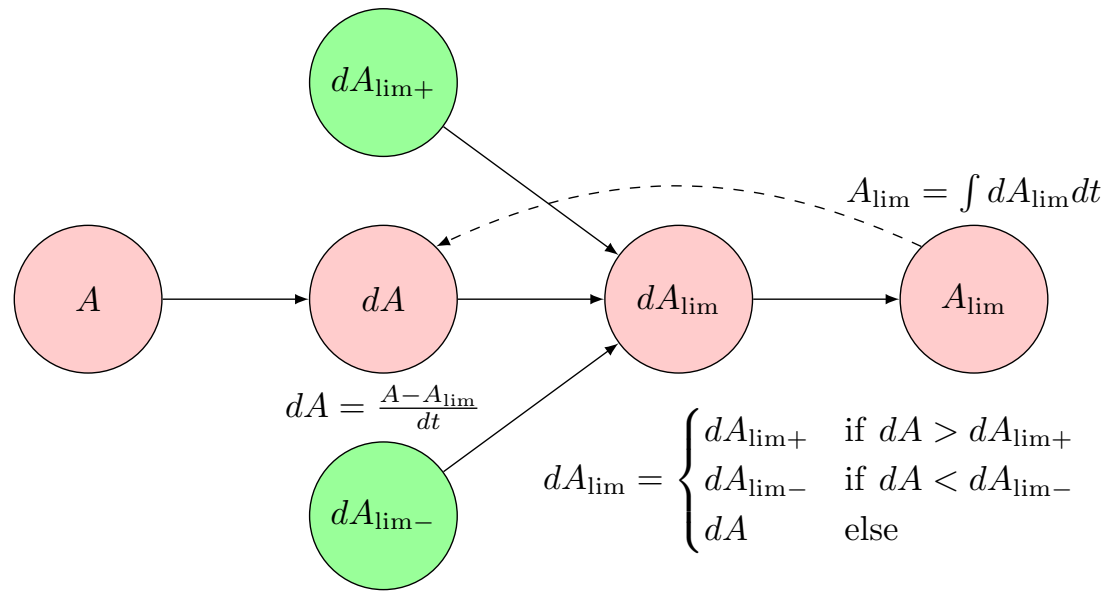

Figure S10: Basic set up of the slew rate limiter for a variable $A$.

\section{S3.4 State observers}

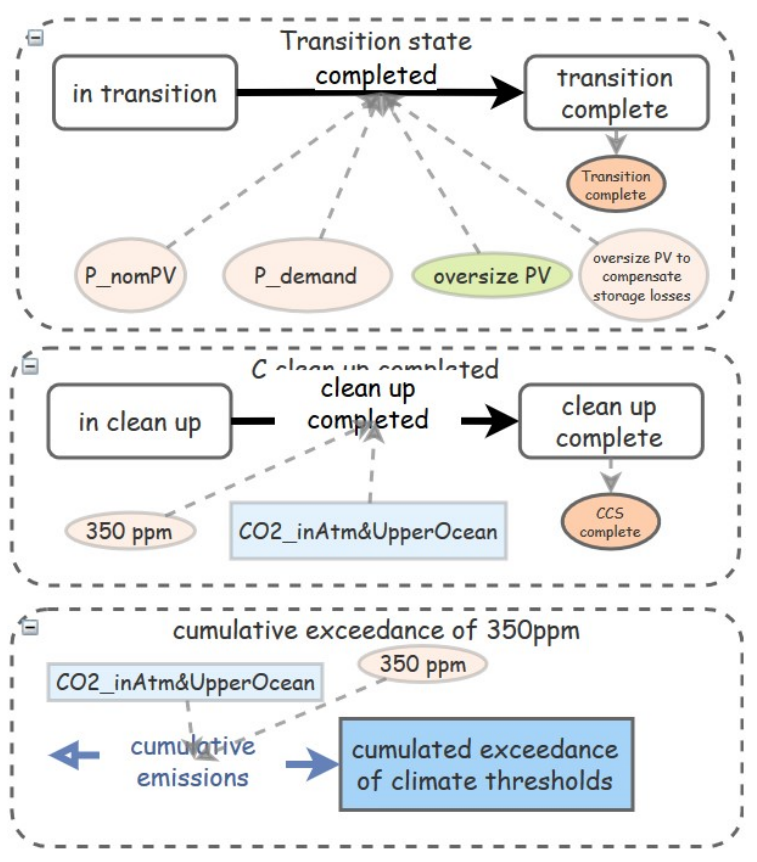

Figure S11: State observers module structure

The state observer modules (Fig. S11) keep track on the fulfillment of the two principal aims of the model:

1. Transition from fossil to solar power supply.

2. Clean-up excess $\mathrm{CO}_{2}$ from the atmosphere and upper ocean until the atmospheric $\mathrm{CO}_{2}$ concentration reaches $350 \mathrm{ppm}$.

Once the installed solar capacity $\left(P_{\text {nomPV }}\right)$ reaches its required size, the energy transition is completed and the fossil engine can be shut down. The state observer Transition state switches to "completed" when this condition is reached. 
The $\mathrm{CO}_{2}$ clean-up is completed when the atmospheric $\mathrm{CO}_{2}$ concentration reaches 350 ppm, which is modelled to be the case once the cumulative emissions are $\leq 1332 \mathrm{Gt}$. In consequence, CCS can be shut down.

Additionally, the cumulative exceedance of $350 \mathrm{ppm}$ is measured by integrating the cumulative emissions curve in excess of $1332 \mathrm{Gt}$ (i. e. $350 \mathrm{ppm}$ ) over time. The value represents only the cumulative exceedance within the simulation time horizon and does not account for contributions in the past and beyond the simulation end.

\section{S4 Carbon cycle}

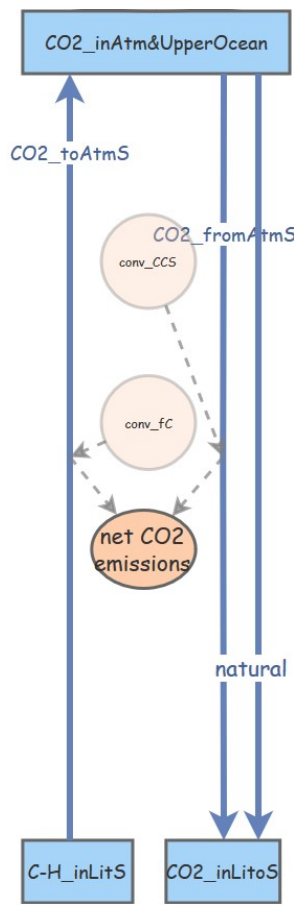

Figure S12: $\mathrm{CO}_{2}$ module structure

Fossil carbon stored in the lithosphere is released as $\mathrm{CO}_{2}$ through combustion of fossil fuels in the fossil engine (see Section S1.1). This emitted $\mathrm{CO}_{2}$ is stored in the atmosphere and, through gas exchange, also in the upper ocean $[83,84]$. Transfer to the deep ocean operates on much longer timescales than the simulation time span and is neglected for simplicity [105]. Some of the $\mathrm{CO}_{2}$ in the ocean is permanently stored in sediments, modelled as a constant flux of $\mathrm{CO}_{2}$ to the lithosphere (natural leak). This constant natural leak is set at $0.8 \mathrm{Gt} / \mathrm{a}$ [84-86], modelling the permanent natural removal through sedimentation and weathering.

Lowering $\mathrm{CO}_{2}$ concentration in the atmosphere causes outgasing of $\mathrm{CO}_{2}$ from the upper ocean [53]. The upper ocean acts as a temporary reservoir and in the model the time lag between the two compartments atmosphere and upper ocean is neglected (see Section S4.1).

Emissions or removal of $18.13 \mathrm{Gt}$ of $\mathrm{CO}_{2}$ to or from the atmosphere and upper ocean causes the atmospheric $\mathrm{CO}_{2}$ concentration to change by $1 \mathrm{ppm}[17,31,106]$. Cumulative $\mathrm{CO}_{2}$ emissions start from 1850 at a pre-industrial $\mathrm{CO}_{2}$ concentration of $276 \mathrm{ppm}$ [17]. Therefore, the $350 \mathrm{ppm}$ threshold [7] corresponds to cumulative emissions of $m_{\mathrm{CO}_{2}}=1332 \mathrm{Gt}$ and the $450 \mathrm{ppm}$ threshold [107] with $m_{\mathrm{CO}_{2}}=3132 \mathrm{Gt}$. The initial value of cumulative $\mathrm{CO}_{2}$ emission is set to $m_{\mathrm{CO}_{2}}=2478 \mathrm{Gt}$, which correspond to $411 \mathrm{ppm}$ in 2020 [17] plus $40 \mathrm{Gt}$ for 2021.

Peak cumulative emissions correlate with induced peak heating [22, 24, 31]. For stabilizing the climate in the long run, atmospheric $\mathrm{CO}_{2}$ concentration needs to be reduced below $350 \mathrm{ppm}$, which is considered a safe limit [7, 12, 107], as fast as possible. The climate related objectives are therefore derived as twofold: (i) minimise peak cumulative emissions alongside with (ii) minimise cumulative exceedance of $350 \mathrm{ppm}$. While the first is commonly used when designing transition models, the second addresses the cumulated 


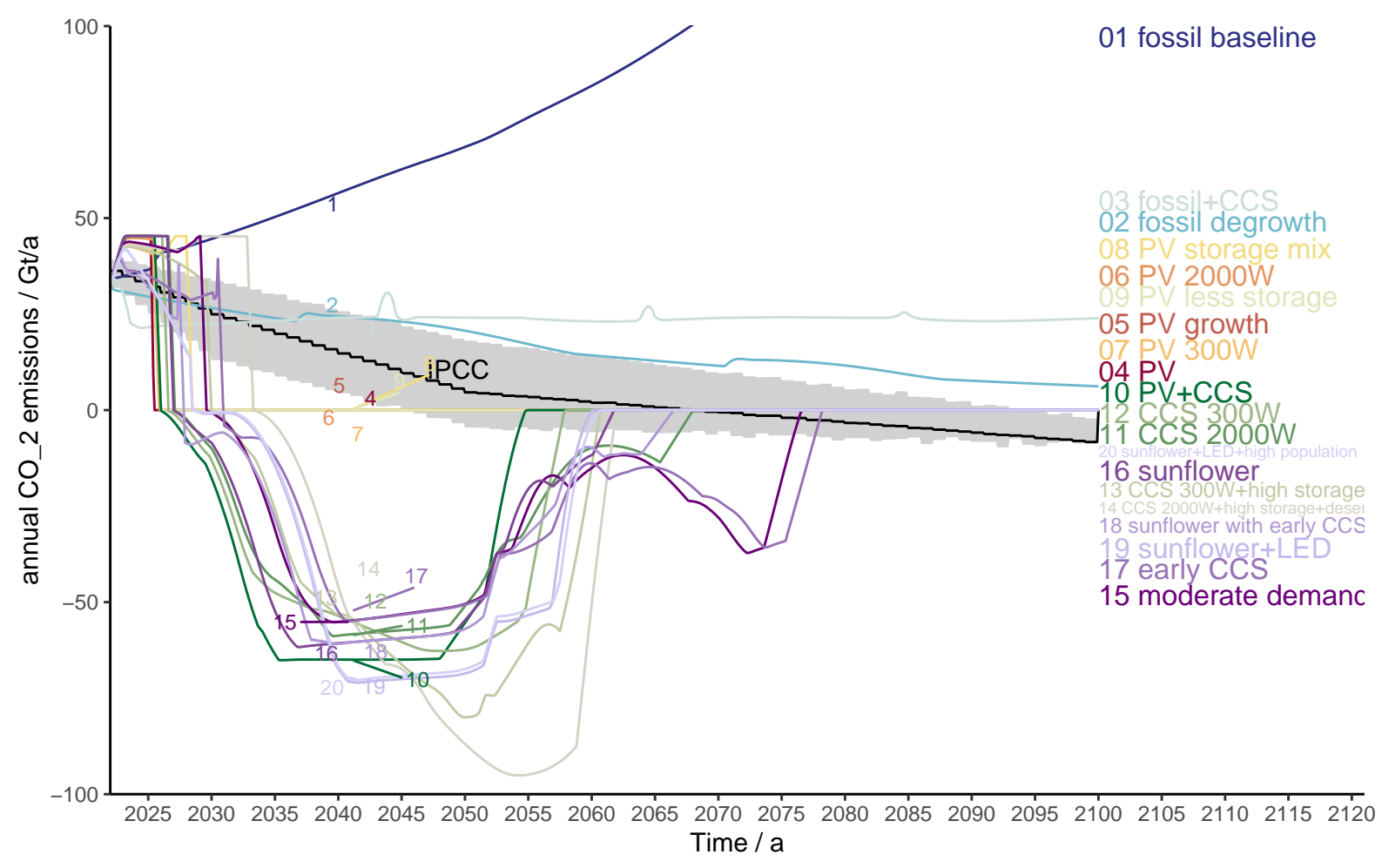

Figure S13: Annual $\mathrm{CO}_{2}$ emissions for all simulation experiments in comparison to IPCC pathways combatible with $1.5^{\circ} \mathrm{C}$ global heating.

pressure on the Earth system from a unsafe climate state. This can be measured through the cumulative exceedance of $350 \mathrm{ppm}$, i. e. the integral of the cumulative emissions exceeding $1332 \mathrm{Gt}$.

The land carbon sink is usually modelled to increase with higher $\mathrm{CO}_{2}$ concentrations due to the $\mathrm{CO}_{2}$ fertilisation effect. However, recent a study finds, that beyond a 3-months average temperature of $25^{\circ} \mathrm{C}$ the biomes become a net source rather than a sink of $\mathrm{CO}_{2}$ [108]. The terrestrial vegetation's carbon mitigation potential may therefore be grossly overestimated. Under current climate scenarios, the tipping point for the terrestrial carbon sink is reached within the next $30 \mathrm{a}$. Therefore, the land carbon sink is excluded in this model.

Fig. S13 shows the annual $\mathrm{CO}_{2}$ emissions for all 25 simulation experiments in comparison with IPCC pathways (grey shaded area). Note, they are fundamentally different in characteristics: initially they are increasing and drop to zero or negative within a very short time, in contrast to a gradual decline as suggested by IPCC pathways.

\section{S4.1 Carbon cycle response to negative emissions}

We tested the response of the carbon cycle to the emission dynamics (positive and negative) of different scenarios in our model. Subsequently, a simple carbon cycle model is integrated capable of approximating the results of Zickfeld et al. [53] (see Fig. S14).

Emissions to the atmosphere are translated into $\mathrm{CO}_{2}$ concentration change with a proportionality relationship, which is linearly proportional to the $\mathrm{CO}_{2}$ concentration in the atmosphere. I.e. the higher the atmospheric $\mathrm{CO}_{2}$ concentration, the larger the proportionality.

$$
\begin{aligned}
\frac{d p_{\mathrm{CO}_{2}}}{d m_{\mathrm{CO}_{2}}}= & \frac{d p_{\mathrm{CO}_{2}, 0}}{d m_{\mathrm{CO}_{2}, 0}}\left(1+a_{d p / d m} \cdot \frac{p_{\mathrm{CO}_{2}}-p_{\mathrm{CO}_{2}, 0}}{p_{\mathrm{CO}_{2}, 0}}\right) \\
& p_{\mathrm{CO}_{2}, 0}=278 \mathrm{ppm} \\
& \frac{d p_{\mathrm{CO}_{2}, 0}}{d m_{\mathrm{CO}_{2}, 0}}=0.058 \mathrm{ppm} / \mathrm{Gt} \\
& a_{d p / d m}=0.35
\end{aligned}
$$




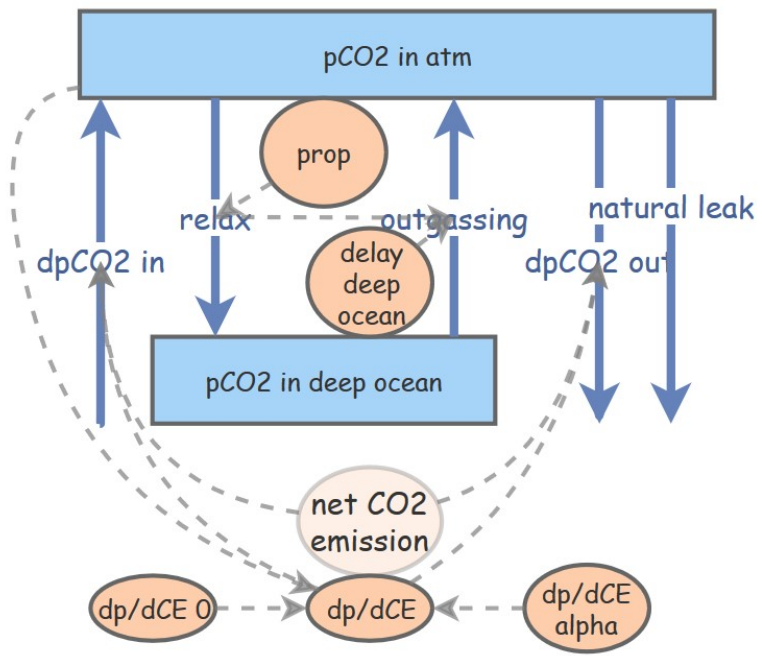

Figure S14: Simple model of the carbon cycle in insightmaker

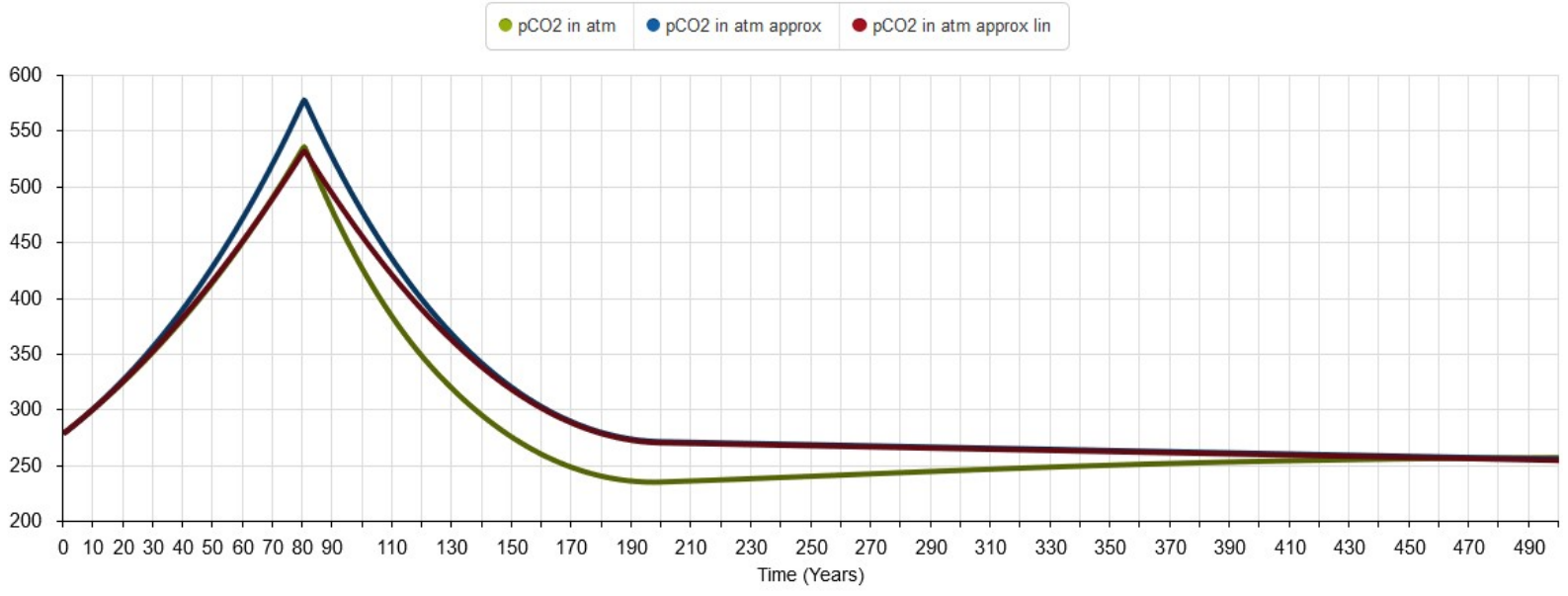

The balance flow between atmosphere and deep ocean is according to an empirically found proportionality of prop $=0.0046 \mathrm{a}^{-1}$ and the time delay for the outflow from deep ocean back to the atmosphere (3rd order delay) is assumed to be $\Delta t_{\text {deep ocean }}=300 \mathrm{a}$ (which is in the range provided by IPCC AR5 [105]).

Figure S15: Comparison of the atmospheric $\mathrm{CO}_{2}$ concentration when considering exchange with deep

\section{ocean (green), when neglecting the deep ocean (blue) and when keeping the proportionality
between atmospheric $\mathrm{CO}_{2}$ concentration and cumulative emissions constant in addition (red). \\ ocean (green), when neglecting the deep ocean (blue) and when keeping the proportionality
between atmospheric $\mathrm{CO}_{2}$ concentration and cumulative emissions constant in addition (red).}

As displayed in Fig. S15, the atmospheric $\mathrm{CO}_{2}$ concentration follows the increase in cumulative emissions proportionally, but decreases faster. However, after negative emissions stop, the $\mathrm{CO}_{2}$ concentration raises again, as $\mathrm{CO}_{2}$ is emitted back from the deep ocean. When neglecting the exchange with the deep ocean (blue), predicted $\mathrm{CO}_{2}$ concentrations are higher at peak but converge after $500 \mathrm{a}$. When additionally neglecting the linear dependency in eq. 16, the predicted concentration is very similar in peak and converges again after 500 a given that $p_{\mathrm{CO}_{2}}<600 \mathrm{ppm}$, which is true for all simulation runs investigated with our model.

The approximated linear and directly proportional correspondence between atmospheric $\mathrm{CO}_{2}$ concentration and cumulative emissions (red line) predicts the peak $\mathrm{CO}_{2}$ concentration correctly and remains above the "true" value for the period of negative emissions until atmosphere and deep ocean are in equilibrium again. I. e. reducing the approximated $\mathrm{CO}_{2}$ concentration below 350 ppm means that the "true" concentration will be even lower (maximum by approximately $50 \mathrm{ppm}$ ) until deep ocean and atmosphere are in equilibrium again. 
Furthermore, as temperature response to negative emissions has the opposite tendency (slight increase when negative emissions commence and slower decrease than linear [53]), temperature will likely not fall below pre-industrial averages even if $\mathrm{CO}_{2}$ concentration falls temporarily below pre-industrial level.

Therefore, it is justified for this simple model to approximate the climate response with the constant proportionality between cumulative emissions and atmospheric $\mathrm{CO}_{2}$ concentration.

\section{S5 Scenario definition}

The energy limits for transition pathways are explored with numerous simulation experiments (Section 4). Parameters are varied for each simulation experiment to find the transition pathway leading to lowest maximum cumulative $\mathrm{CO}_{2}$ emissions throughout the simulation period under the set assumptions. Simulation experiments are defined as parameter sets (see Tables S2 to S4). Each chosen set forms a simulation experiment, which can be described as a scenario narrative (Section 4). The successive simulation experiments evolve similar to a family tree (Fig. S16, Fig. 2).

The following lists some additional rationale descriptions for simulation experiments, complementing the details provided in Section 4:

- Population projections are taken for all scenarios with $50 \%$ confidence [80], except for (25) where $97.5 \%$ confidence is selected.

- (3) fossil CCS: As degrowth ends with energy supply per person below the minimum for a decent life (see (2), this scenario uses a constant demand.

- 7 PV 300W: As demand reduces also after the transition is complete, there is no need for preventive maintenance of PV. PV installed capacity is always big enough to supply demand also during PV replacement cycles.

- (10) PV + CCS: CCS is deployed as direct air capture (DAC), which has a higher energy intensity than capture from stacks $\left(E I_{\mathrm{CCS}}=0.2 \mathrm{TWa} / \mathrm{Gt}[66-70,72]\right)$.

- (15) moderate demand: Storage consists of $56 \%$ batteries, $27 \%$ hydro pumped storage and $17 \%$ synfuels.

\section{S6 Model validation and sensitivity}

Model validity is a critical aspect regarding the (empirical) robustness of simulation results. Barlas [58] distinguishes between structural and behavioral validity of system dynamics models, where structure refers to the model's relationships, equations, as well as parameters, and behavior refers to the trajectories produced by the model through the means of simulation. As the 3-machines model aims to capture the dynamics of an unknown, future transition where little empirical data is available, the focus in model validation lies on structure-oriented tests, such as direct structure tests and structure-oriented behavior tests. Behavior-oriented tests, such as behavior pattern tests were used where feasible (i.e. where data from other, comparable simulation studies was available). In particular, the following tests have been performed throughout the model development process in an iterative manner:

- Structure- and parameter-confirmation tests: Equations, parameter values and data of external variables were derived from literature and are documented in the model.

- Dimensional consistency test: Each variable (primitive in InsightMaker) has a specified unit and InsightMaker is checking the dimensional consistency before running the model.

- Behavior extreme condition tests: Parameters have been varied in their entire feasible range and the simulation results have been checked for feasibility and logical consistency.

- Behavior sensitivity tests: Influential parameters (such as independence time, fraction of demand stored; growth rate, energy demand per person) have been identified and checked whether the simulation results reveal plausible behaviors. 


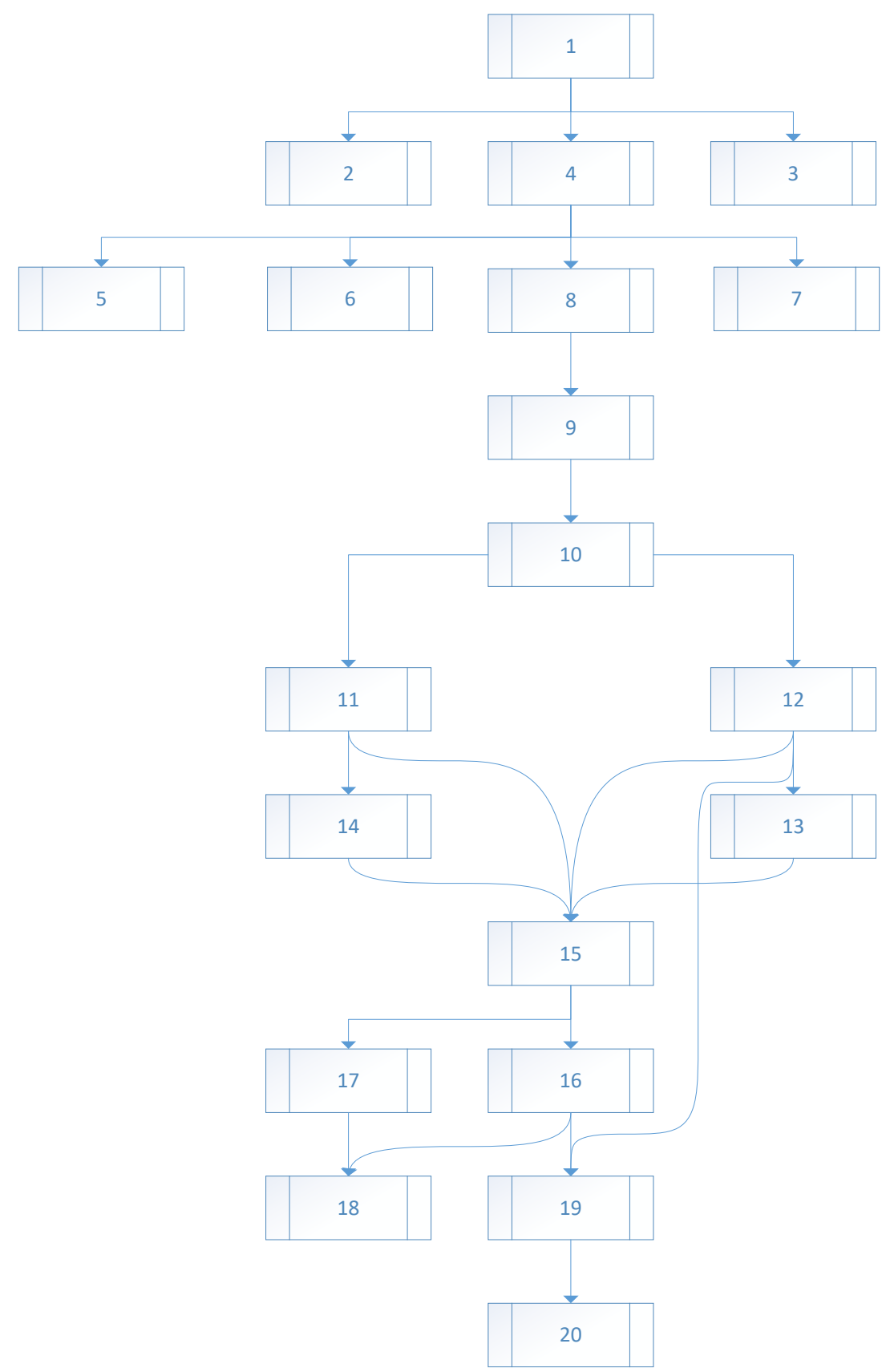

Figure S16: "Family tree" of simulation experiments; simplified version of Fig. 2. 
Table S2: Parameter definition for simulation experiments (1) to (7).

\begin{tabular}{|c|c|c|c|c|c|c|c|c|}
\hline $\begin{array}{l}\text { Scenarios } \\
\text { Variable }\end{array}$ & unit & 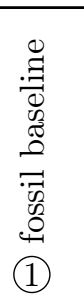 & 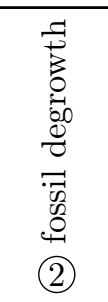 & $\begin{array}{l}\tilde{D} \\
0 \\
0 \\
=7 \\
0 \\
0 \\
0 \\
3\end{array}$ & (4) & 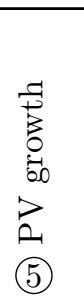 & $\begin{array}{l}3 \\
8 \\
8 \\
\stackrel{2}{8} \\
2 \\
\text { (6) } \\
6\end{array}$ & $\begin{array}{l}3 \\
8 \\
8 \\
8 \\
3 \\
7 \\
7\end{array}$ \\
\hline fC_repair & & 1 & 0 & 1 & 1 & 1 & 1 & 0 \\
\hline CCS switch & & 0 & 0 & 1 & 0 & 0 & 0 & 0 \\
\hline fC switch & & 1 & 1 & 1 & 1 & 1 & 1 & 1 \\
\hline growth rate & & 0.03 & -0.03 & 0 & 0 & 0.03 & & \\
\hline $\begin{array}{l}\mathrm{P}_{\text {_demand }} \text { per } \\
\text { person aim }\end{array}$ & $\mathrm{W} / \mathrm{p}$ & & & & & & 2000 & 300 \\
\hline $\begin{array}{l}\text { demand growth } \\
\text { switch }\end{array}$ & & 1 & 1 & 1 & 1 & 1 & 0 & 0 \\
\hline $\begin{array}{l}\text { demand transi- } \\
\text { tion delay time }\end{array}$ & $\mathrm{a}$ & & & & & & 50 & 7 \\
\hline $\begin{array}{l}\text { demand transi- } \\
\text { tion duration }\end{array}$ & $\mathrm{a}$ & & & & & & 50 & 14 \\
\hline $\begin{array}{l}\text { population confi- } \\
\text { dence selection }\end{array}$ & & 3 & 3 & 3 & 3 & 3 & 3 & 3 \\
\hline $\begin{array}{l}\text { PV repair pro- } \\
\text { portional }\end{array}$ & & & & & & 0.2 & 0.2 & \\
\hline $\begin{array}{l}\text { PV repair on de- } \\
\text { mand }\end{array}$ & & & & & 1 & 0 & 0 & 1 \\
\hline $\begin{array}{lr}\mathrm{PV} & \text { repair } \\
\text { inverse } & \text { propor- } \\
\text { tional } & \end{array}$ & & & & & & 5 & 5 & \\
\hline $\begin{array}{l}\text { beta in transi- } \\
\text { tion }\end{array}$ & & 0 & 0 & 0 & 1 & 1 & 1 & 1 \\
\hline alpha & & 0 & 0 & 0 & 0 & 0 & 0 & 0 \\
\hline oversize PV & & & & & 1.1 & 1.1 & 1.1 & 0.75 \\
\hline $\begin{array}{l}\text { beta after transi- } \\
\text { tion }\end{array}$ & & 0 & 0 & 0 & 0.5 & 0.5 & 0.5 & 0.5 \\
\hline $\begin{array}{l}\text { gamma } \\
\text { epsilon in transi- } \\
\text { tion }\end{array}$ & & 0.95 & 0.95 & $\begin{array}{l}0.6 \\
1\end{array}$ & 0.95 & 0.95 & 0.85 & 0.95 \\
\hline $\begin{array}{l}\text { epsilon after } \\
\text { transition } \\
\text { desert potential } \\
\text { fraction }\end{array}$ & & & & 1 & 0 & & & \\
\hline $\begin{array}{l}\text { independence } \\
\text { time } \\
\text { fraction of daily } \\
\text { demand stored } \\
\text { relative weight } \\
\text { chemical storage } \\
\text { relative weight } \\
\text { mechanical stor- } \\
\text { age } \\
\text { relative weight } \\
\text { electro-chemical } \\
\text { storage }\end{array}$ & $\mathrm{a}$ & 0 & 0 & 0 & 0 & 0 & 0 & 0 \\
\hline
\end{tabular}


Table S3: Parameter definition for simulation experiments (8) to (14).

\begin{tabular}{|c|c|c|c|c|c|c|c|c|}
\hline $\begin{array}{l}\text { Scenarios } \\
\text { Variable }\end{array}$ & unit & $\begin{array}{l}0 \\
80 \\
\sigma \\
\tilde{0} \\
0 \\
0 \\
0 \\
B \\
2 \\
8 \\
8\end{array}$ & 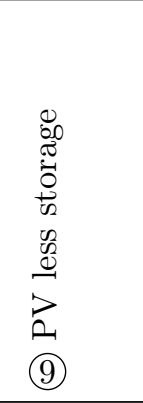 & $\mho_{0}^{2}$ & 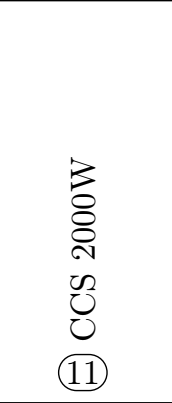 & $\begin{array}{l}3 \\
8 \\
\infty \\
\infty \\
0 \\
0 \\
0 \\
12\end{array}$ & $\begin{array}{l}+ \\
\text { Un } \\
3 \\
8 \\
8 \\
\infty \\
\text { రN } \\
0 \\
0 \\
13\end{array}$ & $\begin{array}{l}+ \\
D \\
D \\
+ \\
\text { on } \\
3 \\
8 \\
8 \\
8 \\
\text { on } \\
\text { on } \\
0 \\
0 \\
14\end{array}$ \\
\hline $\mathrm{fC}$ _repair & & 1 & 1 & 1 & 1 & 1 & 1 & 1 \\
\hline CCS switch & & 0 & 0 & 1 & 1 & 1 & 1 & 1 \\
\hline fC switch & & 1 & 1 & 1 & 1 & 1 & 1 & 1 \\
\hline growth rate & & 0 & 0 & 0 & 0 & 0 & 0 & 0 \\
\hline $\begin{array}{l}\mathrm{P}_{\text {_demand }} \text { per } \\
\text { person aim }\end{array}$ & $\mathrm{W} / \mathrm{p}$ & & & & 2000 & 300 & 300 & 2000 \\
\hline $\begin{array}{l}\text { demand growth } \\
\text { switch }\end{array}$ & & 1 & 1 & 1 & 0 & 0 & 0 & 0 \\
\hline $\begin{array}{l}\text { demand transi- } \\
\text { tion delay time }\end{array}$ & $\mathrm{a}$ & & & & 50 & 7 & 7 & 50 \\
\hline $\begin{array}{l}\text { demand transi- } \\
\text { tion duration }\end{array}$ & $\mathrm{a}$ & & & & 50 & 14 & 14 & 50 \\
\hline $\begin{array}{l}\text { population confi- } \\
\text { dence selection }\end{array}$ & & 3 & 3 & 3 & 3 & 3 & 3 & 3 \\
\hline $\begin{array}{l}\text { PV repair pro- } \\
\text { portional }\end{array}$ & & 0.2 & 0.2 & 0.2 & 0.2 & 0.2 & 0.2 & 0.5 \\
\hline $\begin{array}{l}\text { PV repair on de- } \\
\text { mand }\end{array}$ & & 0 & 0 & 0 & 0 & 0 & 0 & 0 \\
\hline $\begin{array}{lr}\mathrm{PV} & \text { repair } \\
\text { inverse } & \text { propor- } \\
\text { tional } & \end{array}$ & & 15 & 15 & 15 & 15 & 5 & 15 & 20 \\
\hline $\begin{array}{l}\text { beta in transi- } \\
\text { tion }\end{array}$ & & 1 & 1 & 1 & 1 & 1 & 1 & 1 \\
\hline alpha & & 0 & 0 & 0 & 0 & 0 & 0 & 0 \\
\hline oversize PV & & 1.1 & 1.1 & 1.1 & 1.1 & 1.1 & 1.1 & 1.1 \\
\hline $\begin{array}{l}\text { beta after transi- } \\
\text { tion }\end{array}$ & & 0.5 & 0.5 & 0.5 & 0.5 & 0.5 & 0.5 & 0.5 \\
\hline gamma & & 0.95 & 0.95 & 0.95 & 0.95 & 0.95 & 0.95 & 0.95 \\
\hline $\begin{array}{l}\text { epsilon in transi- } \\
\text { tion }\end{array}$ & & & & 1 & 1 & 1 & 1 & 1 \\
\hline $\begin{array}{l}\text { epsilon after } \\
\text { transition }\end{array}$ & & & & 1 & 1 & 1 & 1 & 1 \\
\hline $\begin{array}{l}\text { desert potential } \\
\text { fraction }\end{array}$ & & 0 & 0 & 0 & 0 & 0 & 0 & 0.5 \\
\hline $\begin{array}{l}\text { independence } \\
\text { time }\end{array}$ & $\mathrm{a}$ & 0.01 & 0.0016 & 0.0016 & 0.0016 & 0.0016 & 0.02 & 0.02 \\
\hline $\begin{array}{l}\text { fraction of daily } \\
\text { demand stored }\end{array}$ & & 0.5 & 0.1 & 0.1 & 0.1 & 0.1 & 0.5 & 0.5 \\
\hline $\begin{array}{l}\text { relative weight } \\
\text { chemical storage }\end{array}$ & & 0.5 & 0.5 & 0.5 & 0.5 & 0.5 & 0.5 & 0.5 \\
\hline $\begin{array}{l}\text { relative weight } \\
\text { mechanical stor- } \\
\text { age }\end{array}$ & & 1 & 1 & 1 & 1 & 1 & 1 & 1 \\
\hline $\begin{array}{l}\text { relative weight } \\
\text { electro-chemical } \\
\text { storage }\end{array}$ & & 1 & 1 & 1 & 1 & 1 & 1 & 1 \\
\hline
\end{tabular}


Table S4: Parameter definition for simulation experiments (15) to (20).

\begin{tabular}{|c|c|c|c|c|c|c|c|}
\hline $\begin{array}{l}\text { Scenarios } \\
\text { Variable }\end{array}$ & unit & 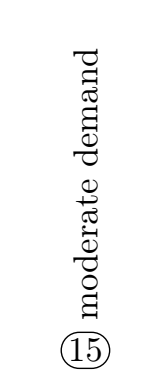 & 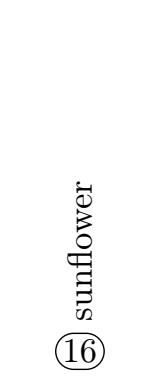 & 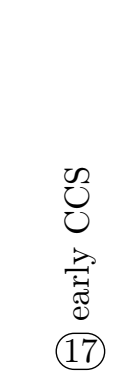 & 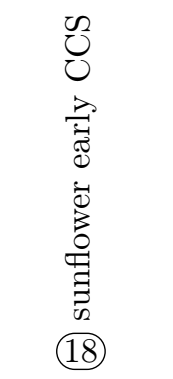 & 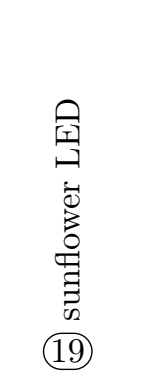 & 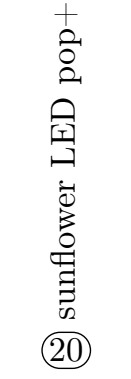 \\
\hline fC_repair & & 1 & 1 & 1 & 1 & 0 & 0 \\
\hline C $\overline{C S}$ switch & & 1 & 1 & 1 & 1 & 1 & 1 \\
\hline $\begin{array}{l}\text { fC switch } \\
\text { growth rate }\end{array}$ & & 1 & 1 & 1 & 1 & 1 & 1 \\
\hline $\begin{array}{l}\mathrm{P}_{\text {_demand }} \text { per } \\
\text { person aim }\end{array}$ & $\mathrm{W} / \mathrm{p}$ & 1400 & 1600 & 1200 & 1600 & 680 & 680 \\
\hline $\begin{array}{l}\text { demand growth } \\
\text { switch }\end{array}$ & & 0 & 0 & 0 & 0 & 0 & 0 \\
\hline $\begin{array}{l}\text { demand transi- } \\
\text { tion delay time }\end{array}$ & $\mathrm{a}$ & 50 & 40 & 50 & 40 & 5 & 5 \\
\hline $\begin{array}{l}\text { demand transi- } \\
\text { tion duration }\end{array}$ & $\mathrm{a}$ & 30 & 30 & 50 & 30 & 10 & 10 \\
\hline $\begin{array}{l}\text { population confi- } \\
\text { dence selection }\end{array}$ & & 3 & 3 & 3 & 3 & 3 & 5 \\
\hline $\begin{array}{l}\mathrm{PV} \text { repair pro- } \\
\text { portional }\end{array}$ & & 0.5 & 0.5 & 0.5 & 0.5 & 0.5 & 0.5 \\
\hline $\begin{array}{l}\text { PV repair on de- } \\
\text { mand }\end{array}$ & & 0 & 0 & 0 & 0 & 0 & 0 \\
\hline $\begin{array}{lr}\mathrm{PV} & \text { repair } \\
\text { inverse } & \text { propor- } \\
\text { tional } & \end{array}$ & & 20 & 20 & 20 & 20 & 20 & 20 \\
\hline $\begin{array}{l}\text { beta in transi- } \\
\text { tion }\end{array}$ & & 1 & 1 & 0.77 & 0.77 & 1 & 1 \\
\hline alpha & & 0 & 0 & 0.2 & 0.2 & 0.8 & 0.8 \\
\hline oversize PV & & 1.1 & 1.1 & 1.1 & 1.1 & 1.1 & 1.1 \\
\hline $\begin{array}{l}\text { beta after transi- } \\
\text { tion }\end{array}$ & & 0.5 & 0.5 & 0.5 & 0.5 & 0.5 & 0.5 \\
\hline gamma & & 0.95 & 0.95 & 0.95 & 0.95 & 0.95 & 0.95 \\
\hline $\begin{array}{l}\text { epsilon in transi- } \\
\text { tion }\end{array}$ & & 1 & 1 & 1 & 1 & 0 & 0 \\
\hline $\begin{array}{l}\text { epsilon after } \\
\text { transition }\end{array}$ & & 1 & 1 & 1 & 1 & 1 & 1 \\
\hline $\begin{array}{l}\text { desert potential } \\
\text { fraction }\end{array}$ & & 0 & 0 & 0 & 0 & 0 & 0 \\
\hline $\begin{array}{l}\text { independence } \\
\text { time }\end{array}$ & $\mathrm{a}$ & 0.01 & 0.0016 & 0.01 & 0.0016 & 0.005 & 0.005 \\
\hline $\begin{array}{l}\text { fraction of daily } \\
\text { demand stored }\end{array}$ & & 0.3 & 0.1 & 0.3 & 0.1 & 0.1 & 0.1 \\
\hline $\begin{array}{l}\text { relative weight } \\
\text { chemical storage }\end{array}$ & & 0.25 & 0.25 & 0.25 & 0.25 & 0.2 & 0.2 \\
\hline $\begin{array}{l}\text { relative weight } \\
\text { mechanical stor- } \\
\text { age }\end{array}$ & & 0.5 & 0.5 & 0.5 & 0.5 & 1 & 1 \\
\hline $\begin{array}{l}\text { relative weight } \\
\text { electro-chemical } \\
\text { storage }\end{array}$ & & 1 & 1 & 1 & 1 & 1 & 1 \\
\hline
\end{tabular}


- Behavior pattern tests: As the energy transition did not happen yet, it is impossible to compare simulation results with empirical data. Instead, the simulation results were compared with simulation outputs from previous modelling exercises [31, 32] (s. next paragraph).

Scenario (4) captures the same scenario as modeled in a previous study: the fastest possible transition from fossil to solar without storage [31]. The study was made with a different mathematical model implemented in Matlab. It can now be compared to the results with the 3-machines model, however, our previous study only focused on the transition alone, therefore comparison is limited to the transition time. The behaviour and tendency is the same during the transition for both models: fastest transition is achieved with maximum fossil investment and no fossil replacement during the transition. This leads to lowest cumulative $\mathrm{CO}_{2}$ emissions. In [31], $1.5^{\circ} \mathrm{C}$ global heating is violated with $20 \%$ at the least, while in the 3-machines model, $1.5^{\circ} \mathrm{C}$ is violated with $8 \%$, if the cumulative distribution function (CDF) is fitted to IPCC Assessment Report 6 data [22]), or $23 \%$, if CDF is fitted to IPCC Special Report $1.5^{\circ} \mathrm{C}$ data [24] (see Fig. S17 and Tab. S5). The latter had been used in the previous study, thus the 3-machines model predicts a slightly slower transition. This is reasonable as the 3 -machines model introduces the dynamic behavior of the ramp up in PV production as well as fossil investments. In conclusion, the 3-machines model predicts the same dynamic behavior as our previous model aiming at the specific simulation experiment (4).

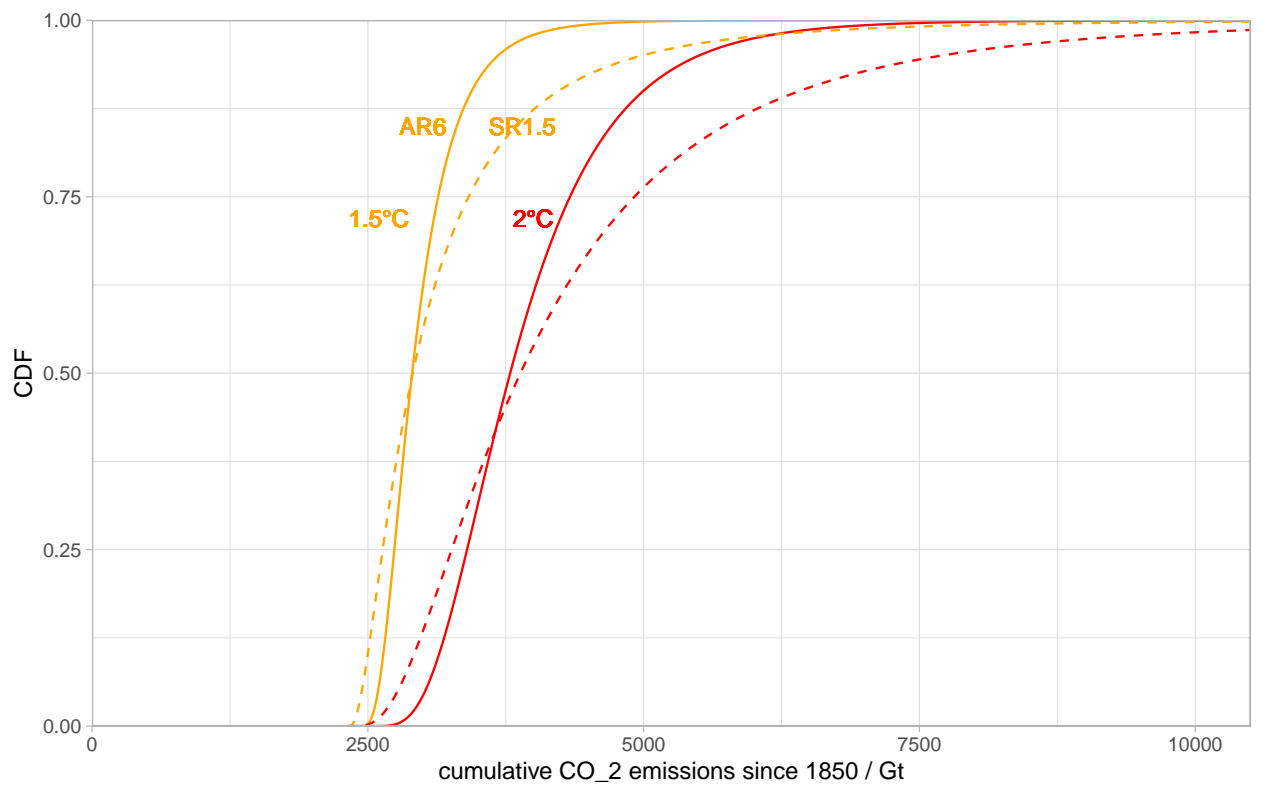

Figure S17: Cumulative density functions (CDF) of the remaining carbon budget for $1.5^{\circ} \mathrm{C}$ (orange) and $2{ }^{\circ} \mathrm{C}$ (red) as a function of cumulative $\mathrm{CO}_{2}$ emissions since 1850. Dashed lines show CDFs fitted to data provided by IPCC special report on $1.5^{\circ} \mathrm{C}[24]$, while solid lines show CDFs fitted to data from IPCC Assessment Report 6 [22].

The value of $d t$ can have real world implications (i.e. if small: system must be able to react fast). Simulation results are more accurate and less oscillating when using the Runge-Kutta algorithm (RK4), however, the difference to simulation runs using Euler are small, especially for integrated results such as cumulative $\mathrm{CO}_{2}$ emissions or cumulative exceedance of $350 \mathrm{ppm}$. Control of the system becomes better with reduced $d t$. Simulations with Runge/Kutta (RK4) takes a bit longer to simulate.

\section{S7 Results from simulation experiments}

The results from the here presented simulation experiments are summarized in Tab. S5, which provides the key numbers for: maximum cumulative $\mathrm{CO}_{2}$ emissions since 1850; cumulative exceedance of $350 \mathrm{ppm}$ throughout the simulation period; transition time since simulation start and year when transition can be competed; clean-up time since simulation start and year when $350 \mathrm{ppm}$ is reached; demand-collapse time since simulation starts and year when demand collapses; fossil fuels consumed throughout the simulation 
period; probability to exceed $1.5^{\circ} \mathrm{C}$ global heating based on data from Assessment Report 6 [22] as used in the main paper; probability to exceed $1.5^{\circ} \mathrm{C}$ global heating based on data from Special Report on $1.5^{\circ} \mathrm{C}[24]$ as used in previous papers [31, 32].

Fig. S18 shows the same data as Fig. 5 but on the x-axis the probability to exceed $1.5^{\circ} \mathrm{C}$ based on data from Assessment Report 6 [22] instead of cumulative $\mathrm{CO}_{2}$ emissions.

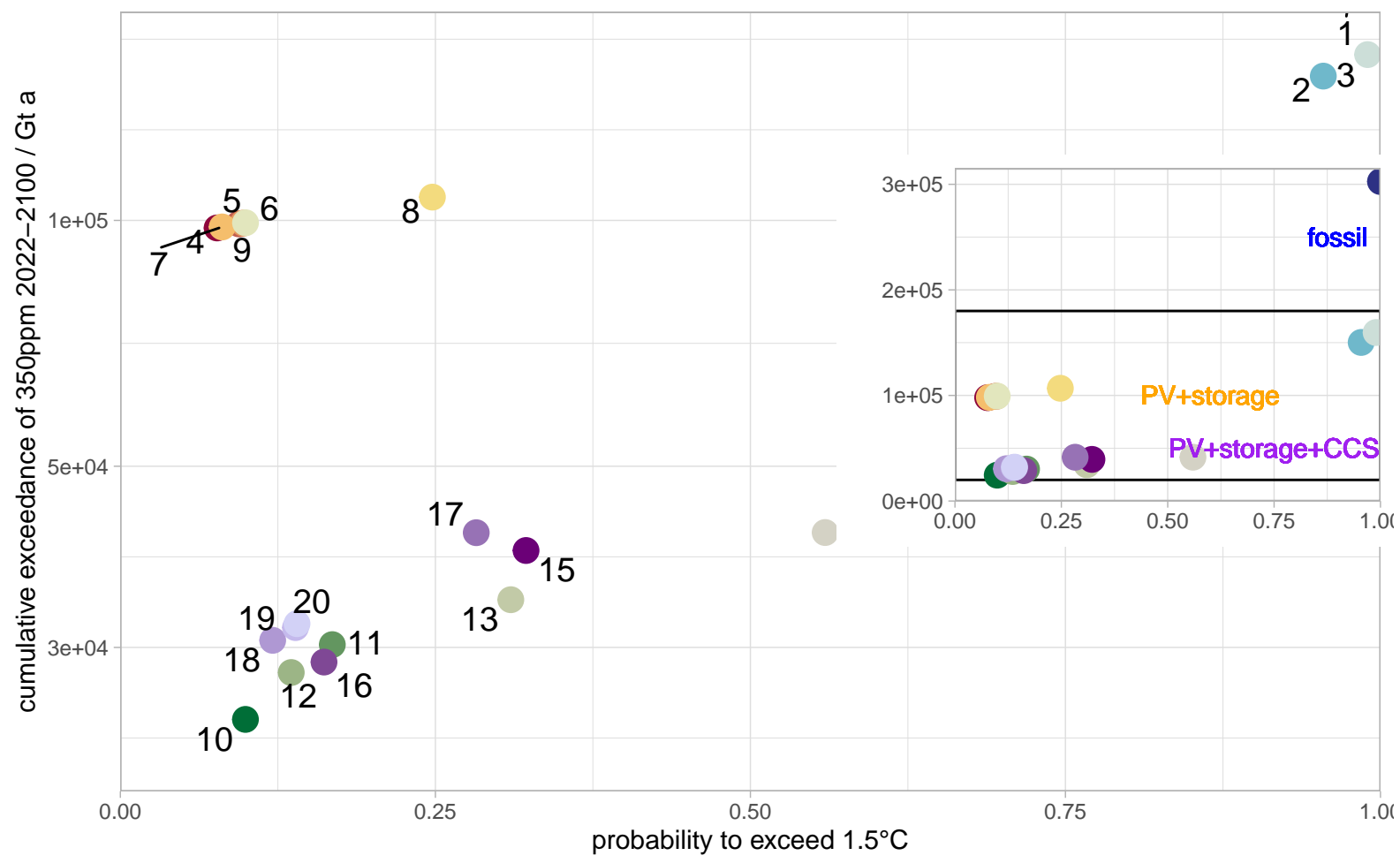

Figure S18: Results of simulation experiments plotted for probability to exceed $1.5^{\circ} \mathrm{C}[22]$ and cumulative exceedance of $350 \mathrm{ppm}$.

Within the first ten time steps of each simulation run, the model transits to the dynamic setting of each simulation experiment. This is due to the fact, that the model is initiated in a steady state for 2021, rather than continuing past dynamics. Within the first year of simulation, the results have therefore no meaning in the real world. As the adaption to the transient state is rather short, this simplification is justified.

\section{S8 Limitations and further research}

Greenhouse gas emissions other than $\mathrm{CO}_{2}$ and their contribution to exceed peak heating as well as for stabilizing the climate are not considered. Land use change would need to be halted completely and reversed, also to restore biodiversity. Negative emissions from reversed land use change and changed land use practises [75] may offset other GHG emissions, such as $\mathrm{CH}_{4}$ from agriculture. Whether they could also have a significant role in the permanent $\mathrm{CO}_{2}$ removal remains to be assessed.

The fossil engine may be operated with synfuels instead of fossil fuels. For instance, to continue operating parts of the fossil infrastructure, which are hard-to-electrify e.g. aviation. Simulations could determine, whether or not synfuels could have a positive effect on the transition. To address this question, a synfuel engine would be added to the energy system, which is supplied with $\mathrm{CO}_{2}$ from CCS and draws power from the grid to synthesis synfuel.

Energy requirements to electrify the current mobility and heat sectors (e.g. retrofitting houses with heat pumps) is not considered in this analysis. This requires an economy-wide analysis of the induced changes in production and consumption patterns, i. e. a detailed look into the energy demand by society. It remains an open area for future research to determine the energetic costs and optimal strategy for this transition. 


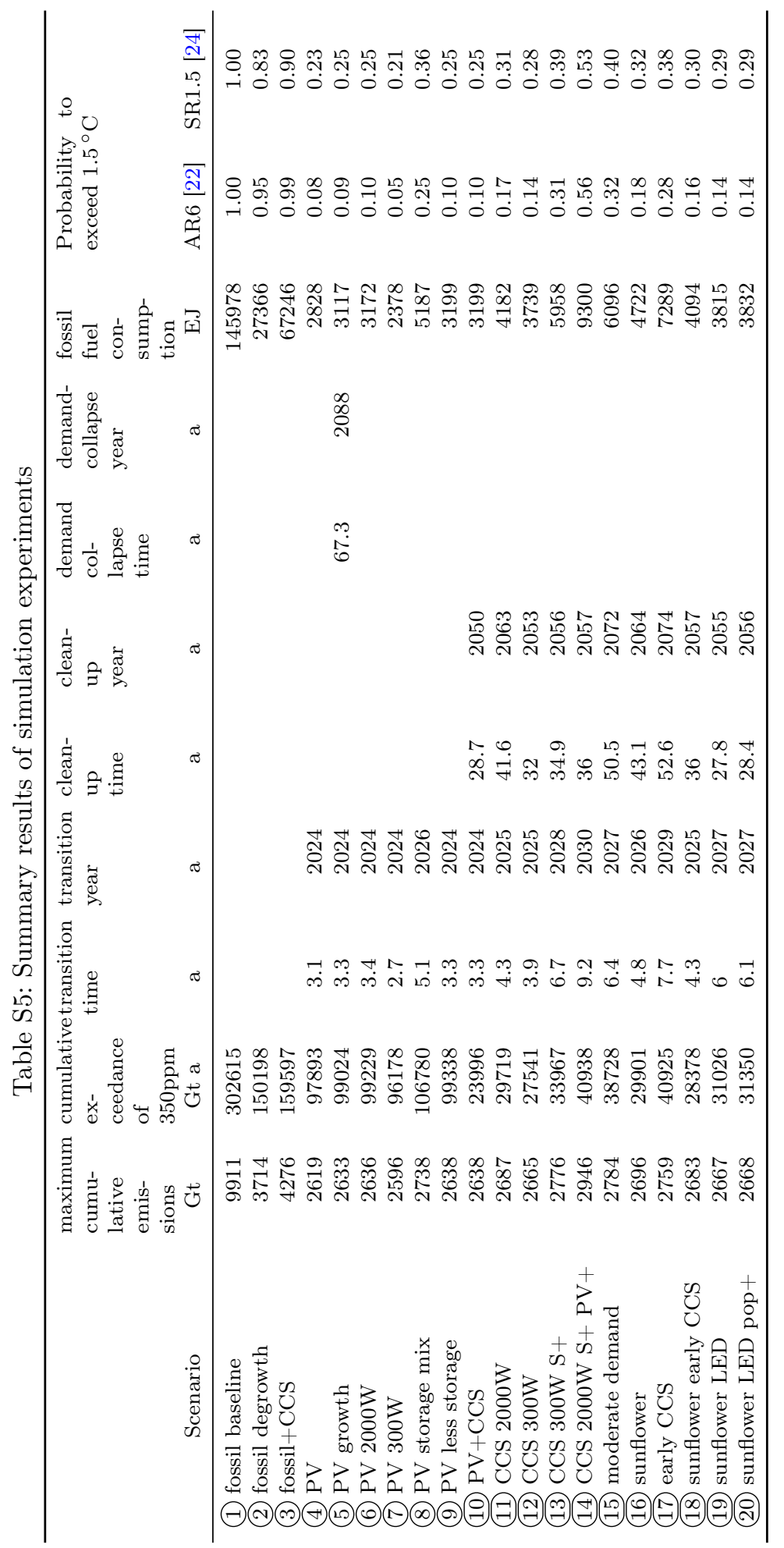


The demand for materials induced by the various scenarios of the 3-machines model may limit the growth of the 3 machines and is another area of future research. Solar PV is seen as non-critical in terms of material demand [31, 50], whereas energy storage technologies may pose serious concerns regarding material availability, most notably for Li and Co in the case of Li-Ion batteries [35, 36]. Pumped-hydro storage will be limited by suitable geographic sites. CCS technologies typically do not require special materials, except for solvents [72]. Still, due to the possible speed of the energy-constrained transition, a detailed assessment of constraints regarding material mobilisation is necessary for all materials involved. These materials can be mobilised from both primary and secondary deposits, most notably from obsolete fossil infrastructure. Material constraints can be included in the model as slew rates or absolute limits.

Regional differences in energy demand patterns, e.g. due to climate and weather conditions, are not considered in this global model. As current energy demand is distributed unequally across the globe (e.g. in Switzerland energy demand is five times higher than the global average), there is a need to redistribute energy demand from "rich" to "poor" both within and across nations ensuring a socially just transition.

\section{S9 IAM overview}

Integrated assessment models (IAM) commonly do not include embodied energy investments [47]. A text search in the documentation of prominent IAMs (MESSAGE [42], IMAGE [43], POLES [44], REMIND [45], TIAM [46]) for the terms "EROI", "net energy", "embodied energy", "energy payback", "energy invest*" confirms that the aspect of investing energy to build renewable energy infrastructure is absent in these models. The POLES model considers EROI only through operational costs (OPEX) for fossil fuels, as their extraction becomes more energy intensive with cumulative production [44]. Simulations in these models are run for times steps between $1 \mathrm{a}$ and 10 a, covering 10 to 57 geographic regions. This temporal and spatial resolution is insufficient to model supply of variable renewables in detail, in particular solar and wind. In contrast, the LUT energy transition model [52], which focuses on the energy system only, matches supply and demand in hourly resolution and for 145 world regions. Still, it does not consider energy investments to build the replacing renewable energy infrastructure. The MEDEAS model [47] is, to the best of our knowledge, the only IAM that considers energy investments.

\begin{tabular}{|c|c|c|c|c|c|}
\hline model & $\begin{array}{l}\text { lead institu- } \\
\text { tion }\end{array}$ & time step / a & world regions & energy investments & source \\
\hline $\begin{array}{l}\text { MESSAGE- } \\
\text { GLOBIOM }\end{array}$ & IIASA & 10 & 11 & no & {$[42]$} \\
\hline IMAGE & $\begin{array}{l}\text { Utrecht Uni- } \\
\text { versity, PBL }\end{array}$ & 1 or 5 & 26 & no & {$[43]$} \\
\hline REMIND-MAgPIE & PIK & 5 or 10 & 12 & no & [45] \\
\hline POLES & JRC & 1 & 57 & no & [44] \\
\hline TIAM-UCL & UCL & 5 or 10 & 16 & no & {$[46]$} \\
\hline WITCH & EIEE & 5 & 17 & no & [109] \\
\hline MEDEAS & $\begin{array}{l}\text { University of } \\
\text { Valladoid }\end{array}$ & 1 & 1 & yes & {$[47]$} \\
\hline C-ROADs & MIT & 1 & 1 to 15 & no & [48] \\
\hline $\begin{array}{l}\text { LUT energy transi- } \\
\text { tion model }\end{array}$ & LUT & 0.000114 & 145 & no & [52] \\
\hline
\end{tabular}

Table S6: Comparison of temporal and spatial resolution and the consideration of energy investments for selected IAMs.

\section{Additional References}

97. Energy information agency. International energy statistics Web Page. 2020. https:// www.eia.gov/international/data/world.
98. International Energy Agency. World energy outlook Report ISBN 9789264449237 (International energy agency, 2020). www.doi.org/10.1787/557a761b-en.

99. Raugei, M., Sgouridis, S., Murphy, D., Fthenakis, V., Frischknecht, R., Breyer, C., 
Bardi, U., Barnhart, C., Buckley, A., Carbajales-Dale, M., Csala, D., de Wild-Scholten, M., Heath, G., Jæger-Waldau, A., Jones, C., Keller, A., Leccisi, E., Mancarella, P., Pearsall, N., Siegel, A., Sinke, W. \& Stolz, P. Energy Return on Energy Invested (ERoEI) for photovoltaic solar systems in regions of moderate insolation: A comprehensive response. Energy Policy 102, 377-384. www . doi.org/10.1016/j.enpol .2016.12.042 (2017).

100. Raugei, M. Energy Return on Investment: Setting the Record Straight. Joule 3, 1810-1811. www.doi.org/10.1016/j.joule. 2019.07.020 (2019).

101. Carbajales-Dale, M., Raugei, M., Fthenakis, V. \& Barnhart, C. Energy Return on Investment (EROI) of Solar PV: An Attempt at Reconciliation [Point of View]. Proceedings of the IEEE 103, 995-999. www . doi.org/10.1109/jproc.2015.2438471 (2015).

102. Fraunhofer Institut for Solar Energy Systems. Photovoltaics report Report (Fraunhofer ISE, 2018). www. ise.fraunhofer.de.

103. Letcher, T. Storing Energy - with special reference to renewable energy sources www . doi .org/10.1016/b978-0-12-8034408.00026-9 (Elsevier, The Netherlands, 2016).

104. Realmonte, G., Drouet, L., Gambhir, A., Glynn, J., Hawkes, A., Koberle, A. C. \& Tavoni, M. An inter-model assessment of the role of direct air capture in deep mitigation pathways. Nat Commun 10, 3277. www . doi .org/10.1038/s41467-019-108425 (2019).

105. IPCC. Assessment Report 5: Climate change 2013, the physical science basis Report (IPCC, 2013).

106. Friedlingstein, P., Jones, M. W., O'Sullivan, M., Andrew, R. M., Hauck, J., Peters, G. P., Peters, W., Pongratz, J., Sitch, S., Le Quéré, C., Bakker, D. C. E., Canadell, J. G., Ciais, P., Jackson, R. B.,
Anthoni, P., Barbero, L., Bastos, A., Bastrikov, V., Becker, M., Bopp, L., Buitenhuis, E., Chandra, N., Chevallier, F., Chini, L. P., Currie, K. I., Feely, R. A., Gehlen, M., Gilfillan, D., Gkritzalis, T., Goll, D. S., Gruber, N., Gutekunst, S., Harris, I., Haverd, V., Houghton, R. A., Hurtt, G., Ilyina, T., Jain, A. K., Joetzjer, E., Kaplan, J. O., Kato, E., Klein Goldewijk, K., Korsbakken, J. I., Landschützer, P., Lauvset, S. K., Lefèvre, N., Lenton, A., Lienert, S., Lombardozzi, D., Marland, G., McGuire, P. C., Melton, J. R., Metzl, N., Munro, D. R., Nabel, J. E. M. S., Nakaoka, S.-I., Neill, C., Omar, A. M., Ono, T., Peregon, A., Pierrot, D.,

Poulter, B., Rehder, G., Resplandy, L., Robertson, E., Rödenbeck, C., Séférian, R., Schwinger, J., Smith, N., Tans, P. P., Tian, H., Tilbrook, B., Tubiello, F. N., van der Werf, G. R., Wiltshire, A. J. \& Zaehle, S. Global Carbon Budget 2019. Earth System Science Data 11, 1783-1838. www . doi .org/10.5194/essd-11-17832019 (2019).

107. Rockström, J., Steffen, W., Noone, K., Persson, A., Chapin, S., Lambin, E., Lenton, T. M., Scheffer, M., Folke, C., Schnellhuber, H., Nykvist, B., De Wit, C. A., Hughes, T., van der Leeuw, S., Rodhe, H., Sörlin, S., Snyder, P., Costanza, R., Svedin, U., Falkenmark, M., Karlberg, L., Corell, R. W., Fabry, V., Hansen, J., Brian, W., Liverman, D., Richardson, K., Crutzen, P. \& Foley, J. Planetary Boundaries: Exploring the Safe Operating Space for Humanity. Ecology and Society 14, 1-33 (2009).

108. Duffy, K. A., Schwalm, C. R., Arcus, V. L., Koch, G. W., Liang, L. L. \& Schipper, L. A. How close are we to the temperature tipping point of the terrestrial biosphere? Science Advances 7.

www .doi.org/10.1126/sciadv . aay 1052 (2021).

109. EIEE. WITCH documentation Web Page. 2019. https :

//www.witchmodel.org/documentation/. 